\title{
The Cross-Section of Currency Order Flow Portfolios*
}

\author{
Lukas Menkhoff $^{\dagger} \quad$ Lucio Sarno $^{\ddagger} \quad$ Maik Schmeling** $^{*} \quad$ Andreas Schrimpf $^{\varsigma}$
}

This version: May 18, 2012

${ }^{*}$ We would like to thank Alessandro Beber, Geir Bjønnes, Jacob Gyntelberg, Joel Hasbrouck, Søren Hvidkjær, Alex Kostakis, Jeremy Large, Albert Menkveld, Roel Oomen, Richard Payne, Lasse Pedersen, Jesper Rangvid, Paul Söderlind, Michel van der Wel, as well as participants at several workshops and seminars for helpful comments and suggestions. We are very grateful to Gareth Berry, Geoffrey Kendrick and UBS for providing us with the proprietary data used in this study, and for numerous conversations on the institutional details of foreign exchange trading at UBS. Sarno acknowledges financial support from the Economic and Social Research Council (No. RES-062-23-2340) and Menkhoff and Schmeling gratefully acknowledge financial support by the German Research Foundation (DFG). The views expressed in this paper are those of the authors and do not necessarily reflect those of the Bank for International Settlements.

${ }^{\dagger}$ Department of Economics, Leibniz Universität Hannover, Königsworther Platz 1, 30167 Hannover, Germany, Tel: +49 511 7624552, Email: menkhoff@gif.uni-hannover.de.

${ }^{\ddagger}$ Cass Business School and Centre for Economic Policy Research (CEPR). Corresponding author: Faculty of Finance, Cass Business School, City University London, 106 Bunhill Row, London EC1Y 8TZ, UK, Tel: +44 207040 8772, Fax: +44 207040 8881, Email: lucio.sarno@city.ac.uk.

${ }^{* *}$ Department of Economics, Leibniz Universität Hannover, Königsworther Platz 1, 30167 Hannover, Germany, Tel: +49 511 7628213, Email: schmeling@gif.uni-hannover.de.

${ }^{\S}$ Bank for International Settlements and CREATES, Centralbahnplatz 2, 4002 Basel, Switzerland. Tel: +4161280 8942. Email: andreas.schrimpf@bis.org. 


\title{
The Cross-Section of Currency Order Flow Portfolios
}

\begin{abstract}
We study the information content of order flow for future exchange rate movements based on a unique dataset covering a broad cross-section of currency pairs and distinguishing key customer types in currency markets. We sort currencies into portfolios based on lagged order flows, and find economically and statistically significant excess returns of up to $15 \%$ per annum for a strategy going long in currencies with recent buying pressure and going short in currencies with recent selling pressure. However, there is substantial heterogeneity across customer types: trading by corporate and private clients is generally not informative and tends to generate negative payoffs. Order flow by asset managers generates the largest portfolio return and forecasts permanent exchange rate changes. Flows by hedge funds also generate a positive portfolio return but only forecast transitory exchange rate movements. Furthermore, currency trading by hedge funds is significantly exposed to default, liquidity, and global volatility risk, which explains part of the forecast power of hedge fund flows for future currency returns.
\end{abstract}

JEL Classification: F31, G12, G15.

Keywords: Order Flow, Foreign Exchange Risk Premia, Heterogeneous Information, Carry Trades, Hedge Funds. 


\section{Introduction}

A recent literature has started to analyze the returns to currency portfolios to investigate the importance of risk factors in the cross-section of currencies and the predictive power of currency characteristics, such as short-term interest rates or lagged returns, for future currency excess returns (Lustig and Verdelhan, 2007; Farhi, Fraiberger, Gabaix, Ranciere, and Verdelhan, 2009; Ang and Chen, 2010; Burnside, Eichenbaum, Kleshchelski, and Rebelo, 2011; Lustig, Roussanov, and Verdelhan, 2011; Barroso and Santa-Clara, 2011; Menkhoff, Sarno, Schmeling, and Schrimpf, 2012a,b). We build on this literature by studying currency order flow portfolios. Specifically, we form portfolios based on currency order flow, i.e. net buying or selling pressure by financial, corporate, and private clients, to test for the predictive information in customer order flows for future currency returns.

The microstructure approach to exchange rates (e.g., Evans and Lyons, 2002a,b) suggests that order flow is crucial for understanding how information is incorporated into exchange rates and exchange rate behavior more generally. This paper sheds new light on the link between order flow and price movements in foreign exchange (FX) markets. Our data, containing customer order flows for several currencies and customer groups, allow us to study the role of order flow as a vehicle for information aggregation in FX markets by testing for the predictive content of order flow for exchange rates. We take the analysis in two new directions. First, we go beyond earlier time-series tests and investigate predictability in a cross-sectional setting by forming portfolios of currencies based on lagged order flows. Second, the data enable us to directly address the question whether order flow might capture exposure to time-varying risk premia in currency markets. We are, to the best of our knowledge, the first to empirically link the predictive ability of order flow for currency returns to observable risk factors in an asset pricing context.

To gauge the impact of order flow on currency excess returns we rely on a simple portfolio approach which allows for straightforward measurement of the economic value of the predictive information contained in order flow. More specifically, we sort currencies into portfolios 
depending on lagged order flow to obtain a cross-section of currency excess returns which mimicks the returns to customer trading behavior and incorporates the information contained in customer order flows. ${ }^{1}$ This information is valuable from an economic perspective: We find that currencies with the highest lagged total order flows (i.e., the strongest net buying pressure across all customer groups against the US dollar) outperform currencies with the lowest lagged flows (i.e., the strongest net selling pressure across all customer groups against the US dollar) by about $10 \%$ per annum.

For portfolios based on disaggregated customer order flow, this spread in excess returns is even more striking. A zero-cost long-short portfolio that mimicks asset managers' order flow yields an average excess return of $15 \%$ p.a., while conditioning on hedge funds' flows leads to a spread of about $10 \%$ per annum. Corporate customers' flows basically generate no spread in returns, and private customers' flows even lead to a highly negative spread (about $-14 \%$ p.a.).

Discriminating between competing explanations for these findings, namely (i) superior processing of fundamental information, (ii) time-varying risk premia, or (iii) liquidity (price pressure) effects, we present evidence that asset managers' flows are associated with permanent shifts in future exchange rates and that their trading positions do not expose them to standard measures of covariance risk. This finding suggests that these key players in FX markets tend to have superior ability to process fundamental information relevant for predicting currency movements. In contrast, hedge funds' flows, while also informative about future currency returns, only forecast transitory exchange rate movements, which is more in line with short-term liquidity effects. In addition, we show that their trading positions are significantly exposed to volatility, liquidity, and default risk. Corporate customers' and private clients' flows largely represent uninformed trading (or "dumb money").

It is well known from the literature that order flow is positively associated with contemporaneous returns in basically all asset classes; see, e.g., Hasbrouck (1991a,b) for stock markets, and Brandt and Kavajecz (2004) for U.S. bonds. This is a stylized fact which

\footnotetext{
${ }^{1}$ Lustig and Verdelhan (2007) were the first to form currency portfolios for cross-sectional asset pricing exercises.
} 
also holds in FX markets, as shown by Evans and Lyons (2002a) and subsequent studies. Regarding the predictive content of order flow for currency returns, the evidence is mixed. A few papers have shown that FX order flow contains information about future currency returns but tend to disagree on the source of this predictive power (e.g., Evans and Lyons, 2005; Froot and Ramadorai, 2005; Rime, Sarno, and Sojli, 2010). ${ }^{2}$ Moreover, other papers fail to find robust predictive power in the first place (Sager and Taylor, 2008). It is also not clear empirically why order flow matters for exchange rates. One strand of literature argues that order flow is causal for returns due to the process of "price discovery", i.e. order flow reveals information which is otherwise dispersed in the economy and only revealed by the trading process (e.g., Evans and Lyons, 2002a; Brandt and Kavajecz, 2004; Evans and Lyons, 2007, 2008). ${ }^{3}$ Another strand of the literature suggests that order flow matters due to downward sloping demand curves or "illiquidity" and, thus, that order flow only has a transitory impact on prices (e.g., Froot and Ramadorai, 2005).

In this paper, we explore these two channels, plus - as a novel feature - also investigate a third possible channel, namely that the forecasting power of order flow stems from exposure to time-varying risk premia. More specifically, we hypothesize that investors dynamically tilt their portfolios towards risky currencies in order to earn the associated currency risk premium, e.g., risk associated with carry trades (Burnside, Eichenbaum, Kleshchelski, and Rebelo, 2011; Lustig, Roussanov, and Verdelhan, 2011; Menkhoff, Sarno, Schmeling, and Schrimpf, 2012a) or liquidity risk premia (Mancini, Ranaldo, and Wrampelmeyer, 2010; Banti, Phylaktis, and Sarno, 2012). Under this scenario, order flow is useful for predicting FX excess returns since positive net buying pressure is associated with higher expected future excess returns which will, on average, lead to a positive correlation between order flow and future currency returns. Naturally, an analysis of this sort requires a long sample and a reasonable cross-section of currencies in order to be able to identify priced risks. Our data are well suited for such an endeavor, which is located at the intersection of market

\footnotetext{
${ }^{2}$ In addition, there is evidence that marketwide private information extracted from equity order flow is useful for forecasting currency returns (Albuquerque, de Francisco, and Marques, 2008).

${ }^{3}$ Available evidence in favor of this mechanism is generally based on rather short-lived, high-frequency price impact studies (e.g., Payne, 2003), or based on showing that order flow and macro news are related (e.g., Evans and Lyons, 2008; Rime, Sarno, and Sojli, 2010).
} 
microstructure and asset pricing.

In short, we show that customer order flow is highly informative about future currency excess returns, even in our out-of-sample setting based on order flow portfolios. This result is robust to several modifications of the empirical setup. Measuring and documenting the statistical and economic significance via a portfolio approach is the first main contribution of our paper.

As a second major contribution, we find that the ability of flows from financial customers to forecast currency returns rests on different economic sources: asset managers' order flows are associated with permanent changes in exchange rates, while returns to portfolios mimicking their trading behavior do not exhibit a meaningful exposure to risk factors. This finding seems to make sense in the light of Evans and Lyons' private information processing hypothesis (e.g., Evans and Lyons, 2002a, 2007, 2008) since asset managers' trading can reasonably be expected to be based on longer-term trends and fundamental developments. Quite distinctly, hedge funds' order flows only forecast transitory exchange rate changes, and returns to order flow-mimicking portfolios at least partly reflect compensation for systematic risk as these portoflios have significant exposure to several systematic risk factors such as carry trade returns (Lustig, Roussanov, and Verdelhan, 2011), volatility risk (Menkhoff, Sarno, Schmeling, and Schrimpf, 2012a), funding illiquidity (the TED spread, see Brunnermeier, Nagel, and Pedersen, 2009), and default risk (spread in AAA and BAA rated bonds). Again, this finding seems reasonable since hedge funds are generally more short-term oriented investors than asset managers, and their trading strategies are designed specifically to earn risk premia in financial markets. Thus, empirical studies testing and explaining why order flow matters for price movements need to account for both information heterogeneity and risk premia. This constitutes the second major contribution of our paper.

The rest of the paper is structured as follows. Section 2 provides a brief discussion of related literature and Section 3 describes our data, Section 4 presents empirical results on the predictive power of order flow, Section 5 investigates competing underlying reasons for why order flow forecasts FX excess returns, and Section 6 presents results of robustness 
tests. Section 7 concludes.

\section{Related literature}

This section briefly discusses strands of literature which are relevant for our research, including studies on the role of order flow in FX markets and recent studies dealing with cross-sectional currency asset pricing based on sorting currencies into portfolios. These two strands of literature developed rather recently and our research is the first, to the best of our knowledge, which studies the role of order flow for currency returns in a cross-sectional setting.

Order flow in FX markets. The study of order flow in FX has a short history. Aside from some early papers which examine the price-setting behavior of single dealers in light of the orders they receive (e.g., Lyons, 1995), the analysis of order flow for market-wide price setting started with Evans and Lyons (2002a). This seminal paper shows that order flow is highly correlated with contemporaneous price changes for two major exchange rates (DEM/USD and Yen/USD), and an important determinant of exchange rates. The intuition underlying this line of research builds on the role of markets in aggregating dispersed information in the process of price discovery. This argument assumes that information about fundamentals does not just exist in the form of public news of macroeconomic data. Rather, there is dispersed information due to, e.g., different interpretations of news about fundamentals or different forecasting ability of future fundamentals on behalf of heterogeneous market participants (Lyons, 2001; Bjønnes and Rime, 2005; Bacchetta and van Wincoop, 2006).

This "information-view" of order flow competes with the "liquidity-view" of order flow. If there is a shortage of liquidity in a specific market, order flow will be positively correlated with price changes. However, the reason is just a shortage of available liquidity, possibly due to short-term inventory considerations of dealers. This constitutes an alternative ex- 
planation for the Evans and Lyons (2002a) finding of a strong contemporaneous relation between order flow and price changes. As a consequence the literature has developed three testable implications which help to distinguish the information-view from the liquidity-view of order flow: (1) It is not order flow in general that is relevant for information aggregation but only order flow of informed agents. (2) The information contained in order flow will impact prices only if this information is not already publicly available. (3) Order flow is informative in that it is the means by which fundamental news get incorporated into prices. We shortly review empirical evidence on these hypotheses.

Disaggregated order flow. The disaggregation of total order flow provides a straightforward way of testing the information-view of order flow. Accordingly, the order flow by informed market participants (often financial institutions) should be related to price changes, whereas order flow by uninformed traders (often corporate customers) should be rather irrelevant. Possible information advantages over other market participants can derive for instance from i) a specific expertise in particular currencies (e.g. Fan and Lyons, 2003; Marsh and O'Rourke, 2005; Osler, Mende, and Menkhoff, 2011), or ii) from being a large market participant (e.g. Menkhoff and Schmeling, 2010; Phylaktis and Chen, 2010; Moore and Payne, 2011), or else iii) location close to FX trading centers (e.g. Ito, Lyons, and Melvin, 1998).

Overall, the evidence in these studies clearly shows that order flow of market participants which can be assumed to be more informed matters more for exchange rates than order flow of small and uninformed market participants.

Privately available order flow. The information view of order flow predicts that publicly available order flow should not matter for price discovery and, hence, exchange rate movements. Sager and Taylor (2008) review studies testing this hypothesis and provide additional evidence based on order flow data which are commercially available to market participants. 
Evans and Lyons (2005) employ six years of data on DEM/USD customer order flow from a large bank. They find that forecasts based on daily order flow dominate a random walk forecast. Froot and Ramadorai (2005) use very different data: the total flow over more than 6 years and 18 currencies channeled by institutional investors via a custodian institution. They apply a vector autoregression (VAR) to decompose the real exchange rate and show that there is a positive relationship between flows and exchange rates in the short run, i.e. up to about 30 days, which reverses afterwards. While both studies (Evans and Lyons, 2005; Froot and Ramadorai, 2005) agree that order flow is related to exchange rate changes, they disagree on the underlying reason: Evans and Lyons (2005) regard order flow as the medium by which information about fundamentals is incorporated into exchange rates so that order flow has permanent price impact, whereas Froot and Ramadorai (2005) argue that the impact of order flow on exchange rates is only transitory and, hence, not related to fundamentals.

An intermediate position is taken by Berger, Chaboud, Chernenko, Howorka, and Wright (2008) who show, based on six years of intraday data, which has hardly been available to market participants at that time, that the relation between cumulative order flow and exchange rate changes becomes weaker for longer horizons, in particular for horizons of more than two weeks. The authors interpret this finding as an indication that liquidity plays an important role in determining the impact of order flow on exchange rates.

Order flow and fundamentals. Some studies also test for the relation between order flow and news about fundamentals. Love and Payne (2008) show that order flow is responsive to macroeconomic news and acts as the vehicle that impounds (the interpretation of) fundamentals into prices (see also Evans and Lyons, 2008; Evans, 2010; Rime, Sarno, and Sojli, 2010). Other papers relate order flow in a structural way to volatility (Berger, Chaboud, and Hjalmarsson, 2009) or consider a structural modeling approach for order flow and fundamentals of a monetary exchange rate model (Chinn and Moore, 2011). ${ }^{4}$

\footnotetext{
${ }^{4}$ Related to this view that order flow is informative about macro fundamentals, Beber, Brandt, and Kavajecz (2011) find that stock market order flow has predictive power for economic activity over the business cycle and bond market returns.
} 
In summary, there is much evidence of heterogeneous information in the FX market. Studies indicate which participants may be better informed and that order flow, in particular order flow by informed agents, may contain valuable information about price behavior.

Our contribution. In this paper we consider a dataset which is ideally suited for studying the underlying economic roots of the link between order flow and exchange rates. The order flow data are disaggregated by key customer types which are a priori likely to be heterogeneous in terms of the information they possess. Importantly, the data cover a broad cross-section of 15 currencies over a very long period compared to previous FX microstructure studies. This allows us to build a bridge between FX microstructure research and cross-sectional currency asset pricing, which has been hampered by data availability in the past. The portfolio approach that we bring to the FX microstructure literature and which has proven useful in cross-sectional FX asset pricing studies (e.g. Burnside, Eichenbaum, Kleshchelski, and Rebelo, 2011; Lustig, Roussanov, and Verdelhan, 2011; Menkhoff, Sarno, Schmeling, and Schrimpf, 2012a) provides a simple and intuitive way to gauge the economic value of order flow for forecasting exchange rates. Most importantly, it helps in studying the (as yet) unexplored question if customer order flow captures risk premia in currency markets associated with e.g. systematic volatility, liquidity, default, or macro risk, or if the forecasting power of order flow for exchange rates is mainly due to liquidity effects or private information. ${ }^{5}$

\section{Data}

Aggregate order flow. We employ a unique dataset based on daily customer order flows for up to 15 currency pairs over a long sample period from January 2, 2001 to May 27, 2011, for a total of 2,664 trading days. Hence, in contrast to much of the earlier literature, we

\footnotetext{
${ }^{5}$ Some earlier papers have looked at the relation between order flow and risk premia in a very different context, at the level of interbank order flows, where risk-averse dealers incorporate a risk premium into their quotes due to a portfolio balance effect from incoming customer order flow (see, e.g., Lyons, 1997; Evans and Lyons, 2005; Killeen, Lyons, and Moore, 2006).
} 
employ order flow from the end-user segment of the FX market and not order flow from the interbank market. This is important since microstructure models suggest that the information in flows stems from trading with customers and not from interbank trading. Order flows in our sample are measured as net buying pressure against the USD, i.e., the U.S. dollar volume of buyer-initiated minus seller-initiated trades of a currency against the USD, and cover all trades of customers (end-users) with UBS during our sample period. A positive number means net buying pressure in the foreign currency relative to the USD. Note that order flows do not measure trading volume but net buying (or selling) pressure, as mentioned above. Aggregate order flows, i.e., aggregated across customers, are available for the following 15 currencies: Australia (AUD), Brazil (BRL), Canada (CAD), the Euro (EUR), Hong Kong (HKD), Japan (JPY), Sweden (SEK), Mexico (MXN), New Zealand (NZD), Norway (NOK), Singapore (SGD), South Africa (ZAR), South Korea (KRW), Switzerland $(\mathrm{CHF})$, and the United Kingdom (GBP). In the following, we refer to these flows as "total flows" since they are aggregated across all customers of UBS. ${ }^{6}$

A natural question is whether order flows from UBS are representative of end-user currency demands in FX markets or not. While this question naturally cannot be answered without knowledge of the customer flows of all other dealers, there are good reasons to believe that the flows employed in our paper are highly correlated with a large portion of end-user order flows. First, UBS is among the largest dealers in FX markets and their average market share (according to the Euromoney FX Survey) over our sample period amounts to about $13 \%$. Over most years of our sample period, UBS was ranked among the top three of all FX dealers (with Deutsche Bank, Barclays and Citi usually being the closest competitors). Thus, UBS clearly represents one of the most important FX dealers and a

\footnotetext{
${ }^{6}$ Our data covers order flow for spot exchange rates. There is anecdotal evidence that some big players in the FX market prefer trading forward contracts for pure currency bets, which would suggest that ideally one would wish to have order flow for both spot and forward exchange rates. However, there is no reason to doubt that our spot order flow data is appropriate for this study for the following reasons. First, the FX microstructure literature has used spot order flow (either interdealer or customer) to document empirically the existence of a strong contemporaneous relationship between FX returns and order flow and to test microstructure theories, starting from the seminal paper of Evans and Lyons (2002a). Second, any FX player (big or small) who expects, for example, a currency to depreciate will trade in the same direction (and hence sell that currency) in either the spot and/or the forward market. In other words, it is reasonable to expect that spot and forward order flows are highly correlated, just like spot and forward FX returns are (approximately $99 \%$ at the daily frequency).
} 
significant portion of the market solely on its own. ${ }^{7}$ Second, a handful of top dealers in FX markets account for more than $50 \%$ of total market share and all of these large dealers essentially have access to the same set of large customers. Hence, it seems very likely that UBS flows' are highly correlated with flows observed at, e.g., Deutsche Bank, Barclays, Citi, or JP Morgan which in turn implies that our order flows are representative of the top end of customer trading in FX markets.

Table 1 shows some descriptive statistics for total flows (in billion USD). The largest average and median daily order flows are for EUR, JPY, and CHF. The largest average daily flow (in absolute value) is the Euro/USD pair where customers (on a net basis) sold on average 63 million EUR against USD per trading day. Hence, average order flows are fairly small relative to gross daily trading volume in FX markets. ${ }^{8}$ The order flow series display a high kurtosis, meaning that there are many extremely large or small order flows in basically all currencies. Daily flows tend to be positively autocorrelated but the degree of autocorrelation is very small. Hence, for all practical purposes, our daily order flow series are unpredictable on the basis of past order flow.

Also, there is a clear pattern in order flow standard deviations. Major currencies, such as the EUR, CHF, JPY, GBP, have much larger variation in order flows and, hence, a larger absolute size of order flows compared to other currencies and especially developing markets. This result is intuitive as there is much more trading in major currencies but it suggests that one cannot easily compare order flows across currencies and that some form of standardization is needed to make sensible comparisons. ${ }^{9}$ We take this into account in

\footnotetext{
${ }^{7}$ Note that most UBS FX customers are in fact big players and include other banks, many large asset management firms and hedge funds, and a large fraction of wealthy private clients. According to the most recent 2011 Euromoney survey, UBS has a particularly high market share in FX business with financial customers (banks, real money and leveraged funds). Admittedly, some fraction of the flow will not reflect directional bets or currency speculation at all, but hedging needs of the customer; this is most likely to be the case for non-financial customers.

${ }^{8}$ To provide a benchmark, daily gross spot turnover in the Euro/USD pair in April 2010 amounted to USD 469 billion according to the most recent FX triennial survey (BIS, 2010). These (gross) figures are based on data collected from about 4,000 reporting dealers worldwide.

${ }^{9}$ In addition, the volatility of individual order flows also varies over time and flows for each currency tend to become increasingly volatile towards the end of the sample. Also for this reason, some form of standardization is necessary.
} 
our empirical analysis below.

\section{TABLE 1 ABOUT HERE}

Finally, aggregate order flows display a high kurtosis (especially the British pound) which is largely driven by some days with extremely high (in absolute value) order flows. Eliminating these few outliers does not change our results reported below.

Customer order flow. We also obtain order flows disaggregated by customer groups for the same sample period, albeit only for a subset of nine major currencies. ${ }^{10}$ There are four customer groups for which flows are available: Asset Managers (AM), Hedge Funds (HF), Corporate Clients (CC), and Private Clients (PC). Asset managers are "real money managers" with a longer investment horizon, hedge funds are leveraged short-term investors, corporate clients are basically non-financial importers or exporters, whereas private clients are individuals with an investable wealth of at least three million USD. Hence, these four customer types are likely to differ considerably in the degree of informedness.

We provide descriptive statistics for these flows separately in Table 2 but here we report averages across all currency pairs for the sake of brevity. Specifically, we report the cross-sectional average of each sample moment along with the 5th and 95th percentile in parentheses and brackets, respectively. We also report results for total flows (T9) based on the same nine developed currencies in the last panel for comparison.

The table shows that average flows across currencies are close to zero for all four customer groups. Flow volatility and kurtosis of flows exhibits a negative correlation. Asset managers' flows have the highest volatility, followed by hedge funds, corporate clients, and private clients but the pattern is reversed for the kurtosis of flows. Hence, asset managers' flows seem to be least driven by extremely large realizations but are somewhat more volatile in

\footnotetext{
${ }^{10}$ The nine currencies are: AUD, CAD, EUR, JPY, SEK, NZD, NOK, CHF, and GBP.
} 
general. Finally, customer flows are positively autocorrelated on average but the magnitude of this autocorrelation is quite low, which is similar to the case for total flows. Hence, our order flow series largely reflect order flow shocks or unanticipated order flow. This is relevant in light of the market microstructure literature which focuses on unanticipated order flow as being relevant for price determination (see, e.g., Hasbrouck, 1991a,b, for an early discussion of this issue).

TABLE 2 ABOUT HERE

Table A.1 in the separate Web Appendix also shows that order flows between customer groups are almost uncorrelated. For example, the correlation between order flows of asset managers and hedge funds is only $-1 \%$ on average across currencies, and the largest correlation (in absolute terms) is only $-10 \%$. This finding of low contemporaneous correlations between flows of different customer types does not change when looking at leads or lags of order flow series, i.e., flows of one customer group do not forecast flows of other customer groups.

Exchange rate returns and excess returns. For our empirical analysis below, we complement these order flow data with daily spot exchange and forward rates from Reuters (available from Datastream). We denote log changes of spot exchange rates as 'exchange rate returns'

$$
\Delta s_{t+1}=s_{t+1}-s_{t}
$$

where lowercase letters refer to logs and all exchange rates are quoted as the USD price of foreign currency, so that positive exchange rate returns correspond to an appreciation of the foreign currency. Hence, a positive correlation of order flows and exchange rate returns means that net buying pressure in the foreign currency (against the USD) is associated with an appreciation of the foreign currency (against the USD) and vice versa. Finally, exchange rate returns from one trading day to the next are based on end-of-day exchange rates and 
not on daily averages.

Since we are interested in the link between order flow and risk premia as well, we also compute currency excess returns which account for the interest rate differential in a foreign currency position. Hence, excess returns $r x$ are given by

$$
r x_{t+1}=s_{t+1}-s_{t}+\left(i_{t}^{\star}-i_{t}\right)
$$

where $i^{\star}$ denotes the foreign interest rate and $i_{t}$ denotes the U.S. interest rate. Since we are working at the daily frequency in our main analysis, we need to obtain daily interest rates for all 15 countries (plus the U.S. interest rate). However, since one-day interest rates are not directly available for all countries in our sample, we employ information in forward rates to infer interest rate differentials directly. Interest rate differentials for horizon $k$ are commonly approximated by $i_{k, t}^{\star}-i_{k, t} \approx s_{t}-f_{k, t}$ where $f_{k, t}$ denotes the log forward rate for horizon $k$ of a given currency. This approximation is exact if covered interest rate parity (CIP) parity holds, which tends to be the case at daily or even shorter horizons (see Akram, Rime, and Sarno, 2008). ${ }^{11}$

For our empirical analysis below, we employ weekly forwards since the weekly frequency gives us a complete coverage of all currencies and we use the simple approximation $s_{t}-$ $f_{1 \text { day }, t}=0.14\left(s_{t}-f_{5 \text { days }, t}\right)$ to convert weekly interest rate differentials to one-day interest rate differentials. While this approximation is not exact, it has the advantage that it is not estimated (by interpolation or bootstrapping). Furthermore, we show below that our results are not driven by relying on this particular method since all results also obtain when examining exchange rate returns directly.

\footnotetext{
${ }^{11}$ There have been violations of this no-arbitrage relation over the recent financial crisis. As we show below, the results in this paper are entirely driven by changes in spot rates, whereas interest rate differentials only play a negligible role. Thus, results in this paper do not depend on whether CIP holds or not.
} 


\section{Empirical Results}

\subsection{Total order flow portfolios}

We rely on a portfolio approach, mimicking the returns to customer FX trading by conditioning on lagged order flow, to assess the economic value of order flow in predicting currency excess returns. As a benchmark test, we first sort currencies into portfolios based on (lagged) total order flows for each currency. More specifically, we sort currencies into five portfolios $\left(P_{1}, P_{2}, \ldots, P_{5}\right)$ depending on their total order flow on day $t$ and compute portfolio excess returns (or spot exchange rate changes) for the following day. In this basic setup, portfolios are rebalanced at the end of each trading day.

Note that these portfolios are computed from the viewpoint of a U.S. investor as each individual portfolio consists of a short position in USD and a long position in a basket of foreign currencies. Taking the return difference between any two portfolios $P_{j}-P_{i}$ thus gives the return of a portfolio short in the basket of foreign currencies in $P_{i}$ and long in the basket of currencies in $P_{j}$, so that the USD component cancels out and the long-short portfolio is dollar-neutral by construction.

Standardizing order flows. Before sorting currencies in portfolios, we have to make sure that order flows are indeed comparable across currencies. As the absolute size of order flows differs across currencies (as shown above in Table 1) it is not sensible to sort currencies based on raw order flows. Hence, it is necessary to standardize flows. We do this by dividing order flows by their standard deviation to remove the difference in absolute order flow sizes across currencies. For robustness, we employ three different standardization procedures, namely: (i) a rolling scheme, (ii) a recursive scheme, and (iii) an in-sample scheme. More specifically, let $x_{j, t}$ denote the order flow of currency $j$ on day $t$. The rolling scheme divides daily flows by their lagged 60-day standard deviation

$$
\widetilde{x}_{j, t}^{R}=\frac{x_{j, t}}{\sigma\left(x_{j, t-59 ; t}\right)}
$$


where $\widetilde{x}_{j, t}^{R}$ denotes order flow standardized over a rolling window. Recursively standardized order flow $\left(\widetilde{x}_{j, t}^{C}\right)$ just divides daily order flows by their standard deviation over the full prior data history up to day $t$

$$
\widetilde{x}_{j, t}^{C}=\frac{x_{j, t}}{\sigma\left(x_{j, 1 ; t}\right)}
$$

and the in-sample scheme divides daily flows by their full sample standard deviation

$$
\widetilde{x}_{j, t}^{I}=\frac{x_{j, t}}{\sigma\left(x_{j, 1 ; T}\right)}
$$

Rolling and recursive standardizations are obviously useful for out-of-sample purposes since they only use information available in real time, whereas the in-sample standardization just serves as a benchmark. Based on these standardizations, we can now compare order flows in the cross-section of currencies and compute excess returns to portfolios sorted on order flow. ${ }^{12}$

Portfolio excess returns. Table 3 shows average annualized excess returns for order flow portfolios $\left(P_{1}, P_{2}, \ldots, P_{5}\right)$, where $P_{1}$ contains the three currencies with the lowest lagged standardized order flow and $P_{5}$ contains the three currencies with the highest lagged standardized order flow. Hence, $P_{5}$ can be thought of as a portfolio of currencies with the highest buying pressure, whereas $P_{1}$ refers to a portfolio with the strongest selling pressure. Column "Av." shows average returns across all currencies in the cross-section and column "BMS" denotes a portfolio which is long in $P_{5}$ and short in $P_{1}$ ("Buying Minus Selling" pressure). We report portfolio excess returns for the full sample period from January 2001 to May 2011, a pre-crisis subperiod from January 2001 to June 2007, and a crisis/postcrisis subperiod from July 2007 to May 2011. Finally, Panel A reports results for the rolling standardization, Panel B shows results for the recursive standardization, while Panel C gives the results for the in-sample standardization.

\footnotetext{
${ }^{12}$ We only standardize with respect to the volatility of flows to make them comparable across customer groups and currencies. We do not standardize with respect to the mean since average flows are small compared to standard deviations. However, additionally removing the mean of order flows does not change our empirical results below and we provide robustness on this issue later.
} 
Results from this exercise are summarized as follows. There is a strong increase in average excess returns when moving from $P_{1}$ to $P_{5}$ for all standardization schemes and all sample periods considered. The spread in excess returns for $P_{5}$ and $P_{1}$, i.e. the excess return of the BMS portfolio, is economically large (between $8.5 \%$ and $14.7 \%$ p.a.) and statistically highly significant. Therefore, order flows carry significant information for future currency excess returns even in an out-of-sample trading strategy setting which only conditions on real-time information. These results demonstrate the economic value for the owner of this (private) information, i.e. the dealer who is able to observe customer order flow.

Table A.2 in the Appendix shows the same exercise for exchange rate changes instead of excess returns to investigate whether our results are mainly driven by the interest rate differential component of excess returns or whether the forecasting power refers to the spot exchange rates. Results in that table clearly show that the patterns in average spot exchange rate changes across portfolios are at least as pronounced as for average excess returns or, if anything, even more pronounced. Hence, order flow is mainly informative about future spot rates and not about interest rate differentials.

Interestingly, the results are relatively stable across subperiods and across standardization schemes. Since we are mainly interested in out-of-sample performance, we will work with the rolling standardization scheme in all future tests. We choose the rolling instead of the recursive scheme, although it has a somewhat lower return spread, since order flow volatility for individual currencies is itself time-varying and tends to increase over time. Due to these effects, a rolling standardization seems the most sensible.

TABle 3 ABOUT HeRE

Tests for return monotonicity. The last two columns "MR" and "Up" in Table 3 additionally report tests for monotonicity of average portfolio excess returns, i.e. whether there is a significantly increasing pattern of average excess returns when moving from $P_{1}$ to $P_{5}$ or 
not. The MR statistic tests for a monotonically increasing return pattern, whereas the Up test is somewhat less restrictive and simply tests for a generally increasing pattern. ${ }^{13}$ These tests are based on Patton and Timmermann (2010), to which we refer for further details; $p$-values reported in the table are based on a stationary bootstrap.

These tests go beyond the standard $t$-test of a zero BMS portfolio return since they take into account the whole cross-section of average portfolio returns. This is interesting since one would intuitively expect an increasing pattern of average portfolio excess returns when moving from $P_{1}$ to $P_{5}$ if order flow is truly informative about future excess returns. This prediction is significantly borne out in the data in most cases. The somewhat less restrictive "Up" test always rejects a flat pattern in favor of an increasing pattern at least at the ten percent significance level or below, whereas the more restrictive "MR" test significantly rejects the null of a decreasing pattern for the rolling and recursive schemes over the full sample period. Hence, there is strong evidence for a significant relationship between order flow and excess returns in the cross-section of currencies at the level of order flow portfolios.

Finally, we plot cumulative excess returns for the BMS portfolio (rolling standardization scheme) in the left panel of Figure 1. As can be seen, excess returns are quite striking and stable for most of the sample period, although somewhat more volatile at the beginning and towards the end of the sample. For future reference, we also plot cumulative BMS excess returns for the subsample of nine major currencies (see Section 3 above) in the right panel of Figure 1.

\section{FiguRE 1 ABOUT HERE}

Summarizing the main results until this point, we find that lagged order flow has con-

\footnotetext{
${ }^{13}$ The MR test requires that the return pattern is monotonically increasing $P_{1}<P_{2}<\ldots<P_{5}$ and formulates the null hypothesis as $H_{0}: \Delta \leq 0$ and the alternative hypothesis as $H_{a}: \min _{i=1, \ldots, 4} \triangle_{i}>0$, where $\Delta$ is a vector of differences in adjacent average portfolio excess returns $\left(P_{2}-P_{1}, P_{3}-P_{2}, P_{4}-P_{3}\right.$, $\left.P_{5}-P_{4}\right)$ and $\triangle_{i}$ is element $i$ of this vector. The Up test formulates the null hypothesis of a flat pattern $H_{0}: \Delta=0$ and the alternative hypothesis as $H_{a}: \sum_{n=1}^{4}\left|\triangle_{i}\right| \mathbf{1}\left\{\triangle_{i}>0\right\}>0$, so that the test is less restrictive and also takes into account the size and magnitude of deviations from a flat return pattern.
} 
siderable cross-sectional predictive power for future excess returns and spot exchange rate changes. It is tempting to view these results as evidence for either (i) order flow aggregating dispersed information, so that our order flow portfolios just mimick the revelation of this information, or (ii) a risk premium in currency returns which order flows are helping to pick up. ${ }^{14}$ We will examine testable implications of these different views in the following sections.

\subsection{Disaggregated order flow portfolios}

If superior information processing or forecasting ability drive our results above, one expects clear differences in the forecasting power of different customers' order flows, depending on the groups' characteristics. Based on earlier research (see, e.g., Fan and Lyons, 2003; Evans and Lyons, 2007, among others), one would expect to see superior information in flows of financial customers, given that non-financial customers do not specialize in FX trading as their core activity. To investigate this, we now build order flow portfolios based on our disaggregated data for customer flows. We closely follow the approach in Section 4.1 with the exception that we only build four portfolios (rather than five) here since we only have disaggregated flows for nine currencies and want to have a minimum of two currencies per portfolio.

Table 4 reports results for the four customer groups: Asset Managers (AM), Hedge Funds (HF), Corporate Clients (CC), and Private Clients (PC). For comparison, we also report results for total flows based on only the same nine currencies from developed countries (denoted T9). ${ }^{15}$ Results are clear-cut. Asset managers' net buying or selling pressure of currencies is the most informative about subsequent exchange rate behavior. Conditioning on asset managers' flows in a portfolio approach generates a cross-sectional spread in excess returns of about $15 \%$ p.a., followed by hedge funds with an annualized spread of about $10 \%$

\footnotetext{
${ }^{14}$ E.g., customers may want to exploit the risk premium associated with specific currencies and continuously tilt their portfolios towards risky currencies and/or their own trading creates a risk premium due to inventory imbalances, liquidity effects, etc.

${ }^{15}$ For robustness, Table A.3 shows results for the rolling standardization scheme when additionally removing the local mean too, and not just the rolling standard deviation. Our results are not affected by this, as might be expected.
} 
p.a., whereas corporate clients' and private clients' flows actually generate a negative spread of about $-4 \%$ and $-14 \%$, respectively. ${ }^{16}$ The results point towards substantial differences in the customers' predictive information and provide a quantitative summary of the value of this information in economic terms.

\section{TABle 4 ABOUt HeRE}

As above, we also present $p$-values for tests of return monotonicity in the last three columns of Table 4. We additionally include the "Down" test of Patton and Timmermann (2010) here (which is equivalent to the "Up" test but tests for a decreasing pattern in average excess returns) since order flow of corporate and private customers seems to negatively forecast excess returns. For this reason, the MR test for corporate and private customers is also modified to test for a monotonically decreasing pattern instead of an increasing pattern.

Results from these tests corroborate the simple $t$-tests for the BMS portfolios. There is a monotonically increasing pattern in average excess returns for portfolios based on asset managers' and hedge funds' flows which is highly significant, a monotonically decreasing pattern in average excess returns for portfolios based on private customers' flows, and marginally significant evidence for a decreasing pattern in portfolios based on corporate flows (only for the "Down" test and at the $9 \%$ significance level).

Hence, it is not the case that all order flow is equal in terms of its information content for exchange rates. Instead, financial customers' flows (asset managers and hedge funds in our sample) account for the positive relation between lagged flows and future exchange rate returns uncovered in the previous section. Corporate clients' flows are more or less uninformative, and private clients' flows even forecast returns negatively. Using total enduser order flow, which is likely to be dominated by financial customers due to their higher

\footnotetext{
${ }^{16}$ Table A.4 shows results for spot exchange rate changes instead of excess returns, which yield similar results.
} 
trading volume ${ }^{17}$, masks these differences and may even lead to wrong inference about the theoretical link between flows and returns. This is because it is not the case that flows unanimously forecast a permanent shift in exchange rates (as, e.g. under an information view) or are associated with an eventual reversal of exchange rates in the future (as, e.g., under a liquidity view where flows drive spot rates which eventually revert back to their fundamentally warranted level). Also, from a practical forecasting point of view, the most relevant information for FX traders with access to order flow information is not necessarily the total order flow but rather the flow of different customer groups.

In a nutshell, what matters for the relation between end-user order flows and future returns are disaggregated data since the information content of flows for future returns varies markedly across customer groups. This first finding squares well with earlier evidence which shows that customer order flow of financial customers is informative about future FX returns (e.g., Froot and Ramadorai, 2005; Evans and Lyons, 2007; Menkhoff and Schmeling, 2010) but does so in a setting with many exchange rates, a long sample period which yields more reliable results, and in an out-of-sample portfolio sorts context which yields results that are directly interpretable in terms of economic significance.

Figure 2 shows cumulative returns for all four customer groups. ${ }^{18}$ It can directly be seen that returns are very different across customer groups, even when comparing, for example, asset managers and hedge funds. Both groups' BMS portfolios generate significant excess returns but returns for hedge funds are much more volatile than those of asset managers. Hence, we will investigate possible sources of these different behaviors of returns below. ${ }^{19}$

\section{Figure 2 ABOUt HERE}

\footnotetext{
${ }^{17}$ This is especially true for the order flow employed in this paper since UBS is one of the largest dealers in FX and has a high proportion of financial customers (relative to corporate clients).

${ }^{18}$ Cumulative excess returns for total order flows of the same nine developed currencies can be found in the right panel of Figure 1, for comparison.

${ }^{19}$ Table A.5 in the separate Web Appendix also shows that excess returns to the BMS portfolios based on different customers' flows are not highly correlated. Hence, the information contained in the different flows seems to stem from different sources.
} 


\subsection{Cross-sectional regressions}

To further learn about the predictive content of customer order flow for future FX returns, we run cross-sectional regressions along the lines of Fama and MacBeth (1973), which allows us to control for other possible determinants of currency excess returns. For example, it could be the case that asset managers' and hedge funds' order flow mimicking portfolios simply reproduce a carry trade (Burnside, Eichenbaum, Kleshchelski, and Rebelo, 2011; Lustig, Roussanov, and Verdelhan, 2011; Menkhoff, Sarno, Schmeling, and Schrimpf, 2012a) or that their order flow just picks up momentum in currency returns (Menkhoff, Sarno, Schmeling, and Schrimpf, 2012b).

Specifically, we run cross-sectional regressions for each day $t(1, \ldots, T)$ in our sample

$$
r x_{j, t}=\alpha_{t}+\beta_{t, O F} O F_{j, t-1}^{c}+\beta_{t, \text { carry }} \Delta i_{j, t-1}+\beta_{t, \text { mom }} \overline{r x}_{j, t-60 ; t-1}+\varepsilon_{j, t},
$$

where $j(1, \ldots, N)$ indexes currencies, $r x$ denotes currency excess returns, $O F^{c}$ denotes order flow of customer group $c, \Delta i$ denotes interest rate differentials (carry trade), and $r x_{t-60 ; t-1}$ denotes average lagged excess returns over the last 60 trading days (short-term momentum). ${ }^{20}$ This procedure yields a time-series of coefficient estimates $\left(\alpha_{t}, \beta_{t, O F}, \beta_{t, \text { carry }}, \beta_{t, \text { mom }}\right)$ and we report means and $t$-statistics for the null hypothesis of a zero mean based on Newey and West (1987) standard errors for the intercept and slope coefficients in Table 5. Note that these regressions are based on individual currency returns and not on portfolio returns.

Results in Table 5 corroborate our results based on portfolio returns above, namely that order flows of asset managers and hedge funds positively forecast future excess returns, whereas private clients' flows negatively forecast returns. Corporate clients' flows show up with a negative sign but the relation is not significantly different from zero.

More important, however, is the fact that the predictive relation between lagged order flow and future FX excess returns remains also very strong when controlling for the two most important predictors of returns in FX markets, interest rate differentials and (short-term)

\footnotetext{
${ }^{20}$ Using other windows of less or more than 60 trading days does not yield qualitatively different results.
} 
momentum. Interest rate differentials show up with a positive sign, i.e., high interest rate currencies deliver high excess returns on average and vice versa, which is in line with the large literature on the forward discount bias (e.g., Fama, 1984); however, interest rate differentials do not drive out the information contained in order flows. Short-term momentum has no

significant predictive power for returns, which is in line with recent evidence in Menkhoff, Sarno, Schmeling, and Schrimpf (2012b), who show that FX momentum strategies are not profitable for major exchange rates over the last decade.

TABLE 5 ABOUT HERE

\section{Understanding the results}

\subsection{Permanent and transitory exchange rate changes}

In order to better understand the driving forces behind our results above, we next investigate whether order flow forecasts returns because it signals permanent shifts in spot exchange rates or whether it merely forecasts transitory movements which are eventually reversed after some time. This question, whether order flow forecasts a permanent or transitory change in prices, is a central theme in the earlier microstructure literature (see Hasbrouck, 1991a,b). A transitory movement is interpreted as suggesting that order flow effects are merely due to liquidity effects which eventually die out, whereas a permanent movement in spot rates would indicate that order flow conveys information about fundamentals. More specifically, a permanent price impact would most probably indicate that order flow is related to changes in expectations about fundamentals given the daily frequency we are working on.

This question is relevant for our analysis since we find significant differences between the forecasting power of different customer groups' order flows. Therefore it is particularly interesting to find out if all (or some) customers' flows signal information relevant for FX 
rates or whether some customer groups' net buying pressure simply exerts price pressure and liquidity effects.

To this end, we apply our portfolio sorts framework as above but now track cumulative exchange rate returns to BMS portfolios for overlapping periods of 30 trading days after portfolio formation. This approach yields a direct estimate of how spot rates move after experiencing high versus low order flows and avoids imposing a specific parametric structure as in earlier approaches (see, e.g., Hasbrouck, 1991a; Payne, 2003) which often rely on VARs based on spot rate returns and order flows.

Figure 3 shows results for spot rate returns and total order flows for the full set of all 15 currencies (left part) and the smaller set of nine major currencies. The solid lines show the cumulative returns in basis points, whereas the shaded areas show $95 \%$ confidence intervals based on a moving-block bootstrap with 1,000 repetitions. Total flows forecast a permanent change in spot rates which is statistically significantly different from zero. Exchange rates

with the highest net buying (selling) pressure appreciate (depreciate) against the USD for approximately three days. Currency returns on the BMS portfolios increase by about 15 basis points over this period and afterwards the effect of the order flow signal levels out. Hence, order flow conveys information and its impact on exchange rates is not reversed.

\section{Figure 3 ABOUT HERE}

This picture changes when looking only at the nine developed currencies, which show the same increasing pattern at the beginning but then start to partially revert back to their former level. After 25 - 30 trading days, the exchange rate settles at about one half of the initial impact of 15 basis points and the confidence interval includes zero. Hence, there is much less evidence for the hypothesis that order flow conveys information about fundamentals when only looking at major developed markets. This finding makes sense, however, since the major currency markets are most probably more researched and more efficient than smaller currency markets so that the scope for superior information processing 
is reduced. ${ }^{21}$ Finally, the results in Figure 3 also show that the predictive power of order flow for future returns does not crucially depend on a forecast horizon of one day because cumulative returns show a rising pattern for the first three days. Hence, our main results above are unlikely to stem from simple timing issues (e.g., flows and returns are not matched exactly) or a simple bid-ask bounce mechanism.

As a natural next step, we also examine the same question separately for disaggregated customer order flows and show results graphically in Figure 4. Findings are clear-cut. The only customer group with a permanent and significant price impact is asset managers. Hedge funds have a positive but transitory impact, corporate clients have no impact at all, and private clients have a transitory negative impact. Given our finding for total flows of the nine major currencies above, it is interesting to see that asset managers flows are indeed associated with permanent spot exchange rate changes. Hence, order flow of asset managers seems most informative and, most probably, based on genuine information about fundamentals. Net buying pressure by hedge funds, on the other hand, is only associated with transitory changes in spot exchange rates which eventually peter out. Their order flow therefore likely corresponds to short-lived information about liquidity and/or risk premia. Also, it seems reasonable that the negative relation between private clients' flows and future spot rates eventually dies out over time. This finding suggests that private clients can be regarded as "dumb money" in FX markets as their flows negatively forecast transitory future exchange rate returns; alternatively, private clients trade partly for reasons other than profiting from FX trading (e.g., hedging or liquidity needs).

\section{Figure 4 ABOUt HERE}

\footnotetext{
${ }^{21}$ This may be interpreted in the context of the adaptive markets hypothesis (see e.g. Neely, Weller, and Ulrich, 2009, for an analysis in FX markets).
} 


\subsection{Order flow portfolios and risk premia}

So far, we have established that customer order flow is informative about future excess returns (and spot rate changes) and that there are strong differences between different segments of end-users. Perhaps most striking is the finding that a clear difference occurs between asset managers' flows and hedge fund flows. Both types of end-users are big players in FX markets so that it is reasonable to think of both groups as "informed" market participants. In line with this intuition, we find that both groups' order flows significantly and positively forecast currency excess returns. We do find, however, that asset managers flows predict long-lived exchange rate changes, whereas the flows by hedge funds only forecast transitory movements. So, where does this difference come from?

A reasonable hypothesis is that asset managers trade on anticipation of longer-term trends and changing macro fundamentals, whereas hedge funds are more short-term oriented and take on different sources of risk exposure to earn returns. We investigate this possibility next by regressing BMS portfolio returns on various risk factors to see whether order flowmimicking portfolios of some customers are more heavily exposed to systematic sources of risk than others.

Table 6 reports results from simple univariate time-series regressions of BMS excess returns on various risk factors, such as the Dollar risk factor $(D O L)$ and the $H M L_{F X}$ factor from Lustig, Roussanov, and Verdelhan (2011), or non-return based factors such as global FX volatility innovations $V O L_{F X}$ (Menkhoff, Sarno, Schmeling, and Schrimpf, 2012a), U.S. term spread innovations TS (Campbell and Shiller, 1991), TED spread innovations TED (Brunnermeier, Nagel, and Pedersen, 2009), default spread DEF (yield difference of BAA rated and AAA rated corporate bonds), U.S. TIPS spread innovations TIPS, U.S. industrial production growth $(I P)$, U.S. real money growth $(M 2)$, and U.S. CPI inflation $(C P I)$. The first two factors $\left(D O L, H M L_{F X}\right)$ are return-based factors, and we employ factor-mimicking 
portfolios for all other factors to convert them into excess returns. ${ }^{22}$ We work at the monthly frequency here since some of these factors are not available on a daily basis and it seems unlikely to detect these underlying risk premia in portfolio returns at very high frequencies. ${ }^{23}$

Panel A of Table 6 first shows results for BMS portfolios based on total flows as a benchmark and we employ the set of nine developed currencies here, since results for disaggregated flows are also based on this set of currencies. ${ }^{24}$ The results show that most factors do not yield much explanatory power with one exception being the Dollar risk factor. The slope coefficient has a negative sign, which means that portfolios based on total flows yield high returns when the excess return for a U.S. investor long in foreign currencies is low. Hence, the BMS portfolio return based on total flows has a negative exposure to (a basket of) foreign currency excess returns.

Panel B shows the same set of results for BMS portfolios based on asset managers' flows. Here, a number of factors produce loadings that are significantly different from zero, most notably (i.e., in terms of $R^{2} s$ ) global exchange rate volatility, real money growth, and the default spread. The coefficient on real money growth has the expected positive sign and is statistically significant. ${ }^{25}$ Hence, this is one piece of evidence that asset managers take on some form of fundamental macro risk. In a similar vein, the coefficient on TIPS spread innovations is negative and marginally significant (at the $10 \%$ level only), which also suggests that portfolios based on asset managers flows do better in times of low inflation expectations, which again points towards a link towards fundamental macro factors.

However, looking at some of the other factors which are more easily interpretable in

\footnotetext{
${ }^{22}$ For each factor, we regress factor realizations on the set of all 15 individual currencies' excess returns to obtain a maximum correlation between factor and mimicking portfolio, and then form the factor-mimicking portfolio return by using the fitted values of this regression (net of the intercept in the regression). This is a standard procedure following the original approach of Breeden, Gibbons, and Litzenberger (1989) and used in the context of FX carry portfolios by Menkhoff, Sarno, Schmeling, and Schrimpf (2012a).

${ }^{23}$ To this end, we simply sum over daily BMS portfolio log excess returns within each month to obtain monthly returns. We do not sort monthly currency returns into portfolios based on monthly order flows, which would be a different set of portfolios.

${ }^{24}$ Results for BMS portfolios based on all 15 currencies can be found in Table A.6 in the Appendix.

${ }^{25} \mathrm{~A}$ standard money-in-the-utility function specification implies a stochastic discount factor that depends on real money growth. Since higher money balances indicate good times for investors, one would expect the slope coefficient to be positive.
} 
terms of "short-term market risk", like $V O L_{F X}, T E D$ spread innovations, and default spread innovations, we find statistically significant coefficients but with rather unexpected signs. More specifically, the BMS portfolio based on asset managers' flows actually provides high returns in periods characterized by global FX volatility shocks $\left(V O L_{F X}\right)$, funding liquidity shocks $(T E D)$, and shocks to default risk $(D E F)$.

In contrast to this, the BMS portfolio based on hedge funds' flows (Panel C) shows a very different behavior and loads significantly positive on $H M L_{F X}$ (i.e., carry trade returns), and significantly negative on global volatility $V O L_{F X}$, the TED spread, and the default spread. In words, BMS portfolio returns based on hedge funds' flows have a significant exposure to carry trade returns, volatility risk, liquidity risk, and default risk, and all slope coefficients of these factors have the expected sign. Hence, the forecast power of hedge funds' order flow stems at least partly from the fact that hedge funds exert net buying pressure in high risk currencies and net selling pressure in low-risk currencies. As a consequence, high returns to the hedge fund BMS portfolio are partly just a compensation for systematic risk.

In addition, these results square well with our findings above that asset managers' flows contain information about permanent spot exchange rate changes, whereas hedge funds' flows do not. The returns to currency portfolios mimicking their trading behavior are more closely related to macro fundamentals, whereas the ones of hedge funds are more closely tied to short-term risks.

\section{TABLE 6 ABOUT HERE}

Different from the results for the two financial customer groups, the results for corporate customers (Panel D) and private clients (Panel D) do not show clear relations of their BMS returns to any of the risk factors. Most coefficients of the risk factors are statistically insignificant and the explanatory power of the regressions in terms of $R^{2} s$ is close to zero.

Table 7 confirms the point above by regressing BMS portfolio returns on the hedge 
fund risk factors of Fung and Hsieh (2001): PTFS Bond lookback straddle return, return of PTFS Currency Lookback Straddle, return of PTFS Commodity Lookback Straddle, return of PTFS Short Term Interest Rate Lookback Straddle, and return of PTFS Stock Index Lookback Straddle. ${ }^{26}$ There is a significantly negative exposure to currency lookback straddle returns for the hedge fund BMS portfolio (and a marginally significant exposure to bonds and short-term interest rates straddles), i.e., hedge funds perform poorly in times of high volatility, whereas the exposure of the asset managers BMS portfolio is positive so that their BMS portfolio is actually a hedge against volatility shocks. Alternatively, lookback straddle returns measure the return to trend-following trading strategies benefiting from big market moves. Hence, asset managers' BMS portfolios are positively correlated with trendfollowing strategies' returns, whereas hedge funds' returns are negatively correlated with returns to trend-following strategies. Different from these results, but in line with findings for the macro-finance risk factors above, the BMS portfolios of corporate and private clients are not related to hedge fund risk factors.

\section{TABLE 7 ABOUT HERE}

A closer look at the cross-section of excess returns. The above time-series analysis suggests that hedge funds' BMS returns load on some risk factors associated with volatility, illiquidity, and default risk. Our results also suggest that asset managers' BMS portfolios actually had an opposite exposure to these risk factors, which seems to indicate that their returns served as hedge against these risks; however, the results for asset managers are less significant. We now further investigate these patterns by fitting an empirical cross-sectional asset pricing model, and take a closer look at the factor loadings in the cross-section of portfolio returns. More specifically, we do not only look at excess returns of BMS portfolios but investigate all four order flow portfolios jointly.

\footnotetext{
${ }^{26}$ Data for these risk factors can be found at http://faculty.fuqua.duke.edu/dah7/DataLibrary/TFFAC.xls.
} 
To do so in a concise manner, we only examine asset managers' and hedge funds' order flow portfolios since there is little evidence for a risk-based explanation for total flows, corporate, and private clients. In addition, we focus on eight risk factors which have been identified as significantly related to BMS excess returns in the above time-series analysis, namely $H M L_{F X}, V O L_{F X}, M 2$, the TED spread, the default spread (DEF), as well as the hedge fund risk factors of Fung and Hsieh (2001) for bonds (BD), currencies (FX), and short-term interest rates (SIR).

A natural exercise to examine a risk-based explanation of portfolio excess returns would be to estimate the price of risk of these different factors in a cross-sectional asset pricing approach. However, we only have four portfolios per customer group, which is a rather small cross-section for formal cross-sectional pricing tests. In addition, since all four portfolios share one common factor due to their USD exposure (all portfolios are short in the USD and long in a basket of foreign currencies) one needs at least one factor (or a common pricing error across portfolios) to capture this common return exposure Lustig, Roussanov, and Verdelhan (2011). Adding such a "Dollar risk factor" to any other risk factor we are actually interested in would mean that we price a cross-section of four portfolios with two parameters, which does not seem sensible due to obvious overfitting problems. ${ }^{27}$ Hence, in our analysis below we simply examine whether the pattern of risk factor loadings across portfolios is compatible with a risk-based explanation or not.

For a risk-based explanation of order flow portfolio returns to be empirically valid, one would expect to see that factor risk loadings (i) are jointly significantly different from zero (Burnside, 2011), and (ii) line up with average portfolio excess returns. Since we know from Table 4 above that average excess returns increase monotonically when moving from $P_{1}$ to $P_{5}$ for both asset managers' and hedge funds' flows, one should see a similarly monotone pattern in risk factor loadings (increasing or decreasing depending on the specific risk factor).

\footnotetext{
${ }^{27}$ The importance of including such a factor (or a common pricing error) to account for the level of currency excess returns is discussed and well documented in several recent papers (e.g. Burnside, Eichenbaum, Kleshchelski, and Rebelo, 2011; Lustig, Roussanov, and Verdelhan, 2011; Menkhoff, Sarno, Schmeling, and Schrimpf, 2012a).
} 
Thus, we first examine the pattern of factor risk loadings across the four order flow portfolios $\left(P_{1}-P_{4}\right)$ separately for both customer groups and all eight factors. To do so, we jointly estimate the time-series betas of all four portfolios for a given risk factor via the GMM moment conditions

$$
\begin{array}{rlr}
E\left[r x_{i, t+1}-\alpha_{i}-\beta_{i} f_{t+1}\right] & =0 & i=1, \ldots, 4 \\
E\left[\left(r x_{i, t+1}-\alpha_{i}-\beta_{i} f_{t+1}\right) f_{t+1}\right] & =0 & i=1, \ldots, 4,
\end{array}
$$

where $r x_{i}$ denotes excess return of portfolio $i, \alpha_{i}$ is an intercept, and $\beta_{i}$ denotes the slope coefficient for one of the risk factors $f_{t+1}$ from the list above. These moment conditions obviously reproduce OLS coefficient estimates for separate time-series regressions of all four portfolios' excess returns on a constant and a given risk factor. We jointly estimate these regression coefficients via GMM only to obtain HAC standard errors and to allow for contemporaneous correlation across regression error terms. Furthermore, it is straightforward to test for the restriction that all four slope coefficients are jointly equal to zero in this system by means of standard Wald tests.

The resulting slope coefficient estimates $\widehat{\beta}_{i}$ are reported in Table 8 for all four portfolios, all eight risk factors, and for both customer groups. Turning to asset managers first (upper part of the table), we find that risk factor loadings are jointly significantly different from zero for all risk factors except the hedge fund bond lookback straddle. However, visual inspection suggests that there is no monotone pattern in factor loadings across portfolios for a given risk factor, so that there is no clear relation between factor loadings and average portfolio excess returns. This informal result is corroborated by a test for monotonicity in factor loadings (row "MR" in Table 8), which tests for an increasing or decreasing pattern in factor loadings depending on the sign of $\widehat{\beta}_{4}-\widehat{\beta}_{1}$. All $p$-values are large so that there is no significant evidence for a monotone pattern in factor loadings across portfolios for any of the eight risk factors.

Results for hedge funds' order flow mimicking portfolios in the lower panel of Table 8 are quite different. While the test for joint significance of factor loadings also rejects the 
null for all risk factors (except the hedge fund bond risk factor BD), we additionally find a clear monotone pattern in risk factor loadings across portfolios for all eight risk factors. This pattern clearly lines up with the monotone pattern in average portfolio excess returns documented in Table 4. The MR tests confirm that this monotonicity in factor loadings is indeed significant.

\section{TABLE 8 ABOUT HERE}

These results corroborate the time-series finding above that excess returns to hedge funds' order flow portfolios are partly compensation for systematic risk and not necessarily due to superior information processing. For asset managers, the cross-sectional evidence somewhat weakens the notion that their returns are a hedge against risk since there is no clear pattern in factor loadings across portfolios consistent with this possibility.

\section{Additional tests and robustness}

\subsection{Can the information in customer order flow be exploited?}

Our analysis above is intentionally quiet on questions of exploitability of order flow information for trading strategies or robustness to transaction costs. This is because our data on customer order flow are not available to participants in the broader market of course and hence cannot form the basis for a trading strategy, except for UBS itself or for a bank with access to similar customer flows. Hence, an interesting issue is whether owners of this type of order flow information, i.e., large FX dealer banks with a large concentration of informed customers, could potentially employ this information by simply piggy-backing the order flow of their customers. ${ }^{28}$

\footnotetext{
${ }^{28}$ Obviously the data should be used in respect of clients confidentiality and the specific compliance agreements governing customers' transactions.
} 
To examine this question, we calculate net excess returns for BMS portfolios based on total flows of all 15 currencies (T15), the nine developed currencies (T9), and all four customer groups by adjusting excess returns for bid-ask spreads. ${ }^{29}$ We adjust for long positions in all BMS portfolios except for corporate clients and private clients, where we adjust for short positions for obvious reasons. Furthermore, we investigate returns to strategies with a portfolio re-balancing frequency from 1 to 10 days. We do this to balance two competing effects: more frequent re-balancing is more likely to fully exploit the short-lived information in flows but also increases total transaction costs. Hence, it seems worthwhile to look at several reasonable re-balancing frequencies.

Figure 5 shows results for total flows based on all 15 currencies (upper panel) and the nine developed currencies (lower panel). The dashed lines give average excess returns (per annum) and 95\% confidence intervals for excess returns before transaction costs to show the effect of different re-balancing periods. The solid line and shaded area show average net excess returns (p.a.) and 95\% confidence intervals when taking transaction costs into account.

For both sets of currencies, we find that exploiting the information in order flows should in practice be feasible. Average excess returns are significantly different from zero for all re-balancing horizons and economically quite attractive even for short frequencies.

\section{FiguRE 5 ABOUT HERE}

Figure 6 repeats this exercise for customer order flow portfolios. The four plots in Figure 6 show that transaction costs do not wipe out profitability of the four BMS portfolios, with

\footnotetext{
${ }^{29}$ The bid-ask spread data available is for quoted spreads and not effective spreads. It is well known that quoted spreads are much higher than effective spreads (Lyons, 2001) so we follow earlier work, e.g. Goyal and Saretto (2009), and employ $50 \%$ of the quoted bid-ask spread as the actual spread. Even this number seems conservative, though. First, banks with access to this kind of customer order flow data are big dealers which are likely to pay very low spreads since they are key market makers. Second, Gilmore and Hayashi (2011) find in a recent study that transaction costs due to bid-ask spreads are likely to be much lower than our $50 \%$ rule. This finding was corroborated by our own conversations with UBS dealers.
} 
the exception of the BMS portfolio based on corporate clients' order flows. This makes sense as returns on the latter portfolio are relatively small. By contrast the asset managers' BMS portfolio is clearly the most interesting because net excess returns are quite robustly different from zero. A rebalancing period between two to six days, however, with a peak at two or three days describes the strategy with highest excess returns after transaction costs. For the hedge fund managers' BMS portfolio, the consideration of transaction costs requires a rebalancing of one to three days. The private clients' BMS portfolio allows rebalancing between a one to four days window.

These results clearly demonstrate the potential value of being able to observe order flow by customers, especially the one by informed customers such as asset managers or leveraged funds. Overall, the consideration of transaction costs does not erase profitability of the BMS portfolios. Thus, information about customer order flow in principle seems exploitable for the own proprietary trading of the dealer. Our results indicate, however, that a daily portfolio rebalancing might be somewhat costly such that rebalancing should instead optimally occur every two or three days.

\section{FIGURE 6 ABOUT HERE}

\subsection{BMS portfolios based on all currencies}

Our BMS portfolios in the empirical analysis were based on corner portfolios from order flow sorts. Another way to test for the predictive power of order flow for currency excess returns is to form a portfolio which takes positions in all currencies (not just those in the corner portfolios) and weights all currencies according to lagged order flow. To this end, we employ the following procedure to form alternative BMS portfolios: for each day $t$, we cross-sectionally standardize order flows (we subtract the cross-sectional mean and divide

by the cross-sectional standard deviation), rescale these cross-sectionally standardized flows 
to sum to two in absolute value, and then use these as weights to form a portfolio held from day $t$ to $t+1$.

Table A.7 in the Web Appendix shows results for total flows (T15 and T9) and customer flows. As can be seen, our findings are qualitatively unchanged when following this alternative procedure which always takes positions in the full cross-section of available currencies. The most obvious difference (relative to our benchmark sorts in Tables 3 and 4) is the somewhat lower average excess return for BMS portfolios based on hedge funds' flows.

\subsection{Sensitivity of portfolio returns to individual currencies}

We next show results for a cross-validation setting in which we form portfolios and compute returns to BMS portfolios in the usual way but always delete one of the available currencies. For example, we delete order flow for the EURUSD cross and compute BMS portfolio returns for the remaining 14 currencies (total order flows) or remaining 8 currencies (customer order flows). This test serves to explore whether one particular currency is driving the impressive returns to the BMS portfolios documented above.

Table A.8 in the Web Appendix summarizes results from this exercise. The first column of this table indicates the currency left out in the computation of average BMS excess returns whereas the next columns report average BMS excess returns $(r x)$ and Newey/West HAC-based $t$-statistics $(t)$ for different sets of order flows (T15, T9, AM, HF, CC, PC). As can be seen, we always find significantly positive average excess returns for BMS portfolios based on total flows, asset managers' flows, and hedge fund flows and significantly negative average excess returns for BMS portfolios based on private clients' flows. Hence, our main findings do not depend strongly on any particular currency. As may be expected, however, some currencies do have a larger impact on average returns than others. For example, the Japanese Yen and Australian Dollar seem important for results based on asset managers' flows, whereas the Swedish kronor and New Zealand dollar are important for the portfolios based on hedge fund flows. Nevertheless, the general conclusion that asset managers' flows 
are more informative than hedge funds' flows in our data, and that private clients' flows forecast excess returns negatively are not affected by these findings.

\subsection{Cross-sectional regressions with additional control variables}

In Section 4.3 above we ran cross-sectional Fama and MacBeth (1973) type regressions on individual currency excess returns to examine whether the predictive information in order flows is robust to controlling for interest rate differentials and short-term (3 months) currency momentum (see Table 5). We found that the effect of order flow is robust.

In this section, we extend the above analysis to consider additional possible determinants of excess returns in the cross-section of currencies. The control variables we examine are interest rate differentials $(\Delta i)$, (lagged) return momentum over one $\left(r x_{1}\right)$, five $\left(r x_{5}\right)$, and 60 $\left(r x_{60}\right)$ days, lagged bid-ask spreads $(b a)$, volatility betas $\left(\beta_{F X}\right)$, Dollar risk factor betas $\left(\beta_{D}\right)$, and $H M L_{F X}$ betas $\left(\beta_{H}\right)$. The three beta measures are obtained as in Lustig, Roussanov, and Verdelhan (2011) and Menkhoff, Sarno, Schmeling, and Schrimpf (2012a). ${ }^{30}$

Hence, our control variables capture information about momentum at higher frequencies, liquidity risk in the currency market (bid-ask spreads, illiquidity betas), global FX volatility risk, movements in the dollar (Dollar risk factor), and carry trade risk $\left(H M L_{F X}\right.$ factor). ${ }^{31}$ The question is whether order flow is still a robust predictor in the cross-section of individual currencies after taking into account proxies of liquidity or volatility risk. To examine this question, we run cross-sectional FMB regressions which always include lagged order flow $\left(O F_{t-1}\right)$ and one of the explanatory variables from the list above (denoted as $\left.x_{t}\right)$ :

$$
r x_{j, t}=\alpha_{t}+\beta_{t, O F} O F_{t-1}^{c}+\beta_{t, x} x_{j, t-1}+\varepsilon_{j, t} .
$$

\footnotetext{
${ }^{30}$ In our cross-sectional regressions, we account for the fact that these betas are estimated in a first step and apply a Shanken (1992) correction as a remedy for this errors-in-variables problem.

${ }^{31}$ We also include the interest rate differential again for completeness since our regression setup in this section always includes only two variables jointly, namely lagged order flow and one of the factors from the list above, and not three factors as in Table 5 above.
} 
Results from these regressions are reported in Table 9 for total flows and all currencies (T15), total flows for the subsample of nine developed markets (T9), and order flows for all four groups of customers. As can be seen, the coefficient of lagged order flow is highly significant and positive for total flows (T15 and T9), asset managers, and hedge funds, not significant for corporate customers, and significantly negative for private customers across all combinations of order flow and risk factors, as expected.

Regarding the control variables, we find that interest rate differentials tend to have a significantly positive coefficient. Apart from this case, there is little evidence that one of these variables matters much in this particular cross-section and sample period.

\section{TABLE 9 ABOUT HERE}

\section{Conclusion}

The role of order flow as a determinant of exchange rate behavior is still an open issue. There is considerable agreement that order flow is contemporaneously related to exchange rate changes. There is also growing evidence that the incorporation of fundamental information into exchange rates occurs partially via order flow. However, there is no fully convincing evidence yet as to (i) whether the information contained in order flow is useful for forecasting exchange rates out-of-sample and, if so, (ii) what the economic source of such a forecasting power of order flow might be. This paper makes substantial progress on both these questions.

We make use of a unique dataset of customer order flow of a leading FX bank over more than 10 years, up to 15 exchange rates vs. the U.S. dollar, and disaggregated into 4 customer groups. These customer order flow data cover a much longer period than those used in previous research on the relation between exchange rates and customer flows, they cover a much broader set of exchange rates than considered previously, and they are disaggregated 
by key customer groups in today's FX markets such as asset management firms, corporations and hedge funds.

We proceed in several steps. First, we illustrate the forecasting power of order flow, for the first time in an out-of-sample exercise across 15 currencies and over more than a decade. The portfolio approach that we put forth provides an intuitive measure of the economic value of this information for the FX dealer who observes customer order flow. Second, we study the forecasting power of flows originating from different customer groups that differ markedly in the extent to which they are informed. In particular, asset managers' flows are most informative about future exchange rates and forecast permanent changes in exchange rates. Hedge funds' order flows, while also informative, show different behavior, however, and only forecast transitory exchange rate changes. In addition, our results demonstrate that corporations and private customers are mostly uninformed market participants. Finally, we explore whether the forecasting power of order flow by asset managers and hedge funds truly reflects superior information processing or whether it is just a manifestation of risk premia. Our test shows that portfolios mimicking hedge funds' order flow are significantly exposed to systematic illiquidity and volatility risks. Hence, returns generated by hedge funds in FX markets can be partially seen as compensation for taking positions in currencies that are risky. Interestingly, this does not apply to the trading by asset managers, where our results are consistent with superior information processing and genuine forecasting ability.

Overall, these findings shed new light on the role of order flow in understanding exchange rate behavior. First, there is substantial information content in customer order flow, which is potentially exploitable for the owner of this information for its own proprietary trading. However, this information is incorporated into market prices over a few days, and therefore does not allow longer-term forecasts. Second, there is substantial heterogeneity in flows both in terms of forecasting power and in terms of the economic source of forecasting power: indeed the information contained in some order flows, notably hedge funds, partly reflects currency risk premia and not necessarily superior information. 


\section{References}

Akram, Q. F., Dagfinn Rime, and Lucio Sarno, 2008, Arbitrage in the foreign exchange market: Turning on the microscope, Journal of International Economics 76, 237-253.

Albuquerque, Rui, Eva de Francisco, and Luis Marques, 2008, Marketwide private information in stocks: Forecasting currency returns, Journal of Finance 63, 2297-2343.

Ang, Andrew, and Joseph Chen, 2010, Yield curve predictors of foreign exchange returns, Working Paper, Columbia University.

Bacchetta, Philippe, and Eric van Wincoop, 2006, Can information heterogeneity explain the exchange rate determination puzzle, American Economic Review 96, 552-576.

Banti, Chiara, Kate Phylaktis, and Lucio Sarno, 2012, Global liquidity risk in the foreign exchange market, Journal of International Money and Finance 31, 267-291.

Barroso, Pedro, and Pedro Santa-Clara, 2011, Beyond the carry trade: Optimal currency portfolios, Working Paper, NOVA School of Business and Economics.

Beber, Alessandro, Michael W. Brandt, and Kenneth A. Kavajecz, 2011, What does equity sector orderflow tell us about the economy? Review of Financial Studies 24, 3688-3730.

Berger, D.W., A.P. Chaboud, S.V. Chernenko, E. Howorka, and J.H. Wright, 2008, Order flow and exchange rate dynamics in electronic brokerage system data, Journal of International Economics 75, 93-109.

Berger, D.W., A.P. Chaboud, and E. Hjalmarsson, 2009, What drives volatility persistence in the foreign exchange market? Journal of Financial Economics 94, 192-213.

BIS, 2010, Triennial central bank survey - report on global foreign exchange market activity in 2010, Bank for International Settlements, Basel.

Bjønnes, Geir H., and Dagfinn Rime, 2005, Dealer behavior and trading systems in foreign exchange markets, Journal of Financial Economics 75, 571-605.

Brandt, Michael W., and Kenneth A. Kavajecz, 2004, Price discovery in the u.s. treasury market: The impact of orderflow and liquidity on the yield curve, Journal of Finance 59, 2623-2654.

Breeden, Douglas T., Michael R. Gibbons, and Robert Litzenberger, 1989, Empirical tests of the consumption-oriented CAPM, Journal of Finance 44, 231-262.

Brunnermeier, Markus, Stefan Nagel, and Lasse Pedersen, 2009, Carry trades and currency crashes, NBER Macroeconomics Annual 2008 23, 313-347. 
Burnside, Craig, 2011, The forward premium is still a puzzle, American Economic Review forthcoming.

— - Martin Eichenbaum, Isaac Kleshchelski, and Sergio Rebelo, 2011, Do Peso problems explain the returns to the carry trade? Review of Financial Studies 24, 853-891.

Campbell, John Y., and Robert J. Shiller, 1991, Yield spreads and interest rate movements: A bird's eye view, Review of Economic Studies 58, 495-514.

Chinn, Menzie D., and Michael Moore, 2011, Order flow and the monetary model of exchange rates: Evidence from a novel data set, Journal of Money, Credit and Banking 43, 15991624.

Evans, Martin D., 2010, Order flows and the exchange rate disconnect puzzle, Journal of International Economics 80, 58-71.

— , and Richard K. Lyons, 2002a, Order flow and exchange rate dynamics, Journal of Political Economy 110, 170-180.

— 2002b, Time-varying liquidity in foreign exchange, Journal of Monetary Economics 49, 1025-1051.

— , 2005, Meese-rogoff redux: Micro-based exchange rate forecasting, American Economic Review, Papers and Proceedings 95, 405-414.

— , 2007, Exchange rate fundamentals and order flow, Working Paper, Georgetown University.

- 2008, How is macro news transmitted to exchange rates? Journal of Financial Economics 88, 26-50.

Fama, Eugene F., 1984, Forward and spot exchange rates, Journal of Monetary Economics 14, 319-338.

— , and James MacBeth, 1973, Risk, return and equilibrium: Empirical tests, Journal of Political Economy 81, 607-636.

Fan, M., and Richard K. Lyons, 2003, Customer trades and extreme events in foreign exchange, in P. Mizen, ed.: Monetary History, Exchange Rates and Financial Markets: Essays in Honour of Charles Goodhart . pp. 160-179 (Edward Elgar: Northampton).

Farhi, Emmanuel, Samuel P. Fraiberger, Xavier Gabaix, Romain Ranciere, and Adrien Verdelhan, 2009, Crash risk in currency markets, Working Paper, MIT Sloan.

Froot, Kenneth A., and Tarum Ramadorai, 2005, Currency returns, intrinsic value, and institutional-investor flows, Journal of Finance 60, 1535-1566. 
Fung, William, and David Hsieh, 2001, The risk in hedge fund strategies: Theory and evidence from trend followers, Review of Financial Studies 14, 313-341.

Gilmore, Stephen, and Fumio Hayashi, 2011, Emerging market currency excess returns, American Economic Journal: Macroeconomics 3, 85-111.

Goyal, Amit, and Alessio Saretto, 2009, Cross-section of option returns and volatility, Journal of Financial Economics 94, 310-326.

Hasbrouck, Joel, 1991a, Measuring the information content of stock trades, Journal of Finance 46, 179-207.

- 1991b, The summary informativeness of stock trades: An econometric analysis, Review of Financial Studies 4, 571-595.

Ito, Takatoshi, Richard K. Lyons, and Michael T. Melvin, 1998, Is there private information in the FX market? Journal of Finance 53, 1111-1130.

Killeen, W.P., Richard K. Lyons, and Michael J. Moore, 2006, Fixed versus flexible: Lessons from ems order flow, Journal of International Money and Finance 25, 551-579.

Love, Ryan, and Richard Payne, 2008, Macroeconomic news, order flows, and exchange rates, Journal of Financial and Quantitative Analysis 43, 467-488.

Lustig, Hanno, Nikolai Roussanov, and Adrien Verdelhan, 2011, Common risk factors in currency markets, Review of Financial Studies 24, 3731-3777.

Lustig, Hanno, and Adrien Verdelhan, 2007, The cross section of foreign currency risk premia and consumption growth risk, American Economic Review 97, 89-117.

Lyons, Richard K., 1995, Tests of microstructural hypotheses in the foreign exchange market, Journal of Financial Economics 39, 321-351.

— 1997, A simultaneous trade model of the foreign exchange hot potato, Journal of International Economics 42, 275-298.

— , 2001, The Microstructure Approach to Exchange Rates (MIT Press: Cambridge).

Mancini, Loriano, Angelo Ranaldo, and Jan Wrampelmeyer, 2010, Liquidity in the foreign exchange market: Measurement, commonality, and risk premiums, Swiss Finance Institute Research Paper No. 09-44.

Marsh, Ian W., and C. O'Rourke, 2005, Customer order flow and exchange rate movements: Is there really information content? Working Paper, Cass Business School. 
Menkhoff, Lukas, Lucio Sarno, Maik Schmeling, and Andreas Schrimpf, 2012a, Carry trades and global foreign exchange volatility, Journal of Finance 67, 681-718. ing. $2012 b$, Currency momentum strategies, Journal of Financial Economics forthcom-

Menkhoff, Lukas, and Maik Schmeling, 2010, Whose trades convey information? evidence from a cross-section of traders, Journal of Financial Markets 13, 101-128.

Moore, Michael, and Richard Payne, 2011, On the existence of private information in FX markets, Journal of Banking and Finance 35, 1250-1262.

Neely, Christopher, Paul Weller, and Joshua M. Ulrich, 2009, The adaptive markets hypothesis: Evidence from the foreign exchange market, Journal of Financial and Quantitative Analysis 44, 467-488.

Newey, Whitney K., and Kenneth D. West, 1987, A simple, positive semi-definite, heteroskedasticity and autocorrelation consistent covariance matrix, Econometrica 55, 703708.

Osler, Carol L., Alexander Mende, and Lukas Menkhoff, 2011, Price discovery in foreign exchange markets, Journal of International Money and Finance 30, 1696-1718.

Patton, Andrew J., and Allan Timmermann, 2010, Monotonicity in asset returns: New tests with applications to the term structure, the CAPM, and portfolio sorts, Journal of Financial Economics 98, 605-625.

Payne, Richard, 2003, Informed trade in spot foreign exchange markets: An empirical investigation, Journal of International Economics 61, 307-329.

Phylaktis, Kate, and L. Chen, 2010, Asymmetric information, price discovery and macroeconomic announcements in FX market: Do top trading banks know more? International Journal of Finance and Economics 15, 228-246.

Rime, Dagfinn, Lucio Sarno, and Elvira Sojli, 2010, Exchange rates, order flow and macroeconomic information, Journal of International Economics 80, 72-88.

Sager, Michael, and Mark P. Taylor, 2008, Commercially available order flow data and exchange rate movements: Caveat emptor, Journal of Money, Credit and Banking 40, $583-625$.

Shanken, J., 1992, On the estimation of beta pricing models, Review of Financial Studies $5,1-34$. 
Table 1. Descriptive Statistics for Order Flows

This table shows descriptive statistics for total order flows for the 15 currencies in our sample. Flows are measured in billions USD and all currencies are against the USD. A positive (negative) flow means that there is net buying (selling) pressure for the respective currency. The frequency is daily and the sample is from January 2001 to May 2011. Currencies included are the Australian Dollar (AUD), Canadian Dollar (CAD), Swiss Franc (CHF), Euro (EUR), Great Britain Pound (GBP), Japanese Yen (JPY), Norwegian Krone (NOK), New Zealand Dollar (NZD), Swedish Krona (SEK), Brazilian Real (BRL), Hong Kong Dollar (HKD), (South) Korean Won (KRW), Mexican Peso (MXN), Singapore Dollar (SGD), and South African Rand (ZAR).

\begin{tabular}{lrrrrrrr}
\hline & Mean & Median & Std & Skew & Kurt & AC(1) & $p$-val. \\
\hline \multicolumn{7}{c}{ Panel A. Developed countries } \\
\hline AUD & -0.003 & -0.001 & 0.197 & -2.69 & 55.89 & -0.01 & $(0.15)$ \\
CAD & 0.007 & 0.003 & 0.169 & 1.98 & 43.02 & 0.00 & $(1.00)$ \\
CHF & 0.020 & 0.012 & 0.324 & 0.11 & 74.88 & 0.02 & $(0.00)$ \\
EUR & -0.063 & -0.041 & 0.656 & -3.31 & 79.53 & 0.03 & $(0.00)$ \\
GBP & -0.001 & -0.002 & 0.484 & -5.82 & 270.70 & 0.01 & $(0.03)$ \\
JPY & 0.027 & 0.019 & 0.412 & 1.88 & 55.87 & 0.03 & $(0.00)$ \\
NOK & 0.003 & 0.000 & 0.067 & 0.60 & 49.20 & 0.08 & $(0.00)$ \\
NZD & -0.002 & 0.000 & 0.070 & -1.78 & 51.30 & 0.14 & $(0.00)$ \\
SEK & 0.001 & 0.000 & 0.070 & 1.60 & 39.84 & 0.01 & $(0.04)$ \\
\hline \multicolumn{7}{c}{} & \multicolumn{7}{c}{ Developing countries } & & \\
\hline BRL & -0.004 & 0.000 & 0.068 & -1.15 & 30.50 & 0.03 & $(0.00)$ \\
HKD & 0.006 & 0.000 & 0.079 & 2.32 & 35.39 & 0.01 & $(0.02)$ \\
KRW & -0.005 & 0.000 & 0.070 & -0.15 & 59.45 & 0.05 & $(0.00)$ \\
MXN & -0.002 & 0.000 & 0.049 & -0.67 & 27.78 & 0.06 & $(0.00)$ \\
SGD & 0.000 & 0.000 & 0.068 & -4.39 & 110.15 & 0.06 & $(0.00)$ \\
ZAR & 0.002 & 0.000 & 0.068 & -0.91 & 36.38 & 0.16 & $(0.00)$ \\
\hline
\end{tabular}


Table 2. Descriptive Statistics for Order Flows: Customer Groups

This table shows descriptive statistics for customer order flows which are available for the nine major markets in our sample, i.e., the Australian Dollar (AUD), Canadian Dollar (CAD), Swiss Franc (CHF), Euro (EUR), Great Britain Pound (GBP), Japanese Yen (JPY), Norwegian Krone (NOK), New Zealand Dollar (NZD), Swedish Krona (SEK). Flows are measured in billions (in USD) and all currencies are against the USD. A positive (negative) flow means that there is net buying (selling) pressure in the foreign currency against the USD. We report means, medians, standard deviations, skewness, kurtosis, and first-order autocorrelation coefficients $(\mathrm{AC}(1))$ for all four customer groups' flows and, for comparison, for total order flow in the nine currencies (T9). The first number in each cell corresponds to the cross-sectional mean across currencies (e.g., the mean across time-series standard deviations of all nine currencies), whereas the second (parentheses) and third (brackets) number correspond to the $5 \%$ and $95 \%$ percentile of the cross-sectional distribution (across currencies), respectively. The frequency is daily and the sample is from January 2001 to May 2011.

\begin{tabular}{rrrrrr}
\hline Mean & Median & Std & \multicolumn{1}{c}{ Skew } & Kurt & AC $(1)$ \\
\hline \multicolumn{7}{c}{ Panel A. Asset Managers } \\
\hline-0.001 & -0.001 & 0.272 & -0.827 & 80.0 & 0.034 \\
$(-0.063)$ & $(-0.041)$ & $(0.067)$ & $(-5.820)$ & $(39.8)$ & $(-0.009)$ \\
{$[0.027]$} & {$[0.019]$} & {$[0.656]$} & {$[1.978]$} & {$[270.7]$} & {$[0.140]$} \\
\hline \multicolumn{7}{c}{ Panel B. Hedge Funds } \\
\hline 0.002 & 0.001 & 0.205 & -0.738 & 125.1 & 0.032 \\
$(-0.004)$ & $(-0.002)$ & $(0.054)$ & $(-7.977)$ & $(17.5)$ & $(-0.117)$ \\
{$[0.009]$} & {$[0.005]$} & {$[0.494]$} & {$[4.810]$} & {$[271.0]$} & {$[0.128]$} \\
\hline \multicolumn{7}{c}{ Panel C. Corporate clients } \\
\hline-0.003 & -0.001 & 0.171 & -1.091 & 176.8 & 0.004 \\
$(-0.028)$ & $(-0.022)$ & $(0.036)$ & $(-23.273)$ & $(11.0)$ & $(-0.107)$ \\
{$[0.012]$} & {$[0.010]$} & {$[0.387]$} & {$[12.143]$} & {$[898.1]$} & {$[0.091]$} \\
\hline \multicolumn{7}{c}{ Panel D. Private Clients } \\
\hline-0.003 & -0.003 & 0.068 & -0.137 & 208.8 & 0.072 \\
$(-0.049)$ & $(-0.038)$ & $(0.009)$ & $(-17.616)$ & $(22.2)$ & $(-0.025)$ \\
{$[0.007]$} & {$[0.006]$} & {$[0.165]$} & {$[10.063]$} & {$[638.8]$} & {$[0.192]$} \\
\hline \multicolumn{7}{c}{ Panel E. Total flows (T9) } \\
\hline 0.003 & 0.002 & 0.091 & -2.857 & 225.0 & 0.024 \\
$(-0.001)$ & $(0.000)$ & $(0.009)$ & $(-30.643)$ & $(16.2)$ & $(-0.106)$ \\
{$[0.014]$} & {$[0.012]$} & {$[0.265]$} & {$[5.212]$} & {$[1,385.8]$} & {$[0.075]$} \\
\hline \multicolumn{7}{c}{}
\end{tabular}


Table 3. Order Flow Portfolios: Excess Returns

This table shows average annualized portfolio excess returns for five portfolios $\left(P_{1}, \ldots, P_{5}\right)$ sorted on lagged order flow. Sorting is done based on standardized total flows of all customers. Column "Av" shows average excess returns across all currencies, column "BMS" (bought minus sold) reports average excess returns to investing in $P_{5}$ and shorting $P_{1}$. Flows are standardized by their standard deviation (i) using a rolling window over the previous 60 trading days (Panel A), (ii) using a recursive scheme with 60 days initialization horizon (Panel B), and (iii) their in-sample standard deviation. Numbers in brackets are t-statistics based on Newey-West standard errors. Columns 'MR' and 'Up' report p-values for tests of return monotonicity. The frequency is daily and the sample is from January 2001 to May 2011.

\begin{tabular}{|c|c|c|c|c|c|c|c|c|c|}
\hline \multicolumn{10}{|c|}{ Panel A. Rolling window } \\
\hline & $P_{1}$ & $P_{2}$ & $P_{3}$ & $P_{4}$ & $P_{5}$ & Av. & BMS & MR & $\mathrm{Up}$ \\
\hline \multirow{2}{*}{ Jan 2001 - May 2011} & 0.82 & 1.05 & 6.15 & 6.77 & 11.13 & 5.18 & 10.31 & $(0.01)$ & $(0.01)$ \\
\hline & {$[0.29]$} & {$[0.37]$} & {$[2.23]$} & {$[2.40]$} & {$[4.04]$} & {$[2.20]$} & {$[4.05]$} & & \\
\hline \multirow[t]{2}{*}{ Jan 2001 - Jun 2007} & 2.14 & 4.21 & 5.06 & 6.02 & 11.84 & 5.85 & 9.69 & $(0.00)$ & $(0.04)$ \\
\hline & {$[0.71]$} & {$[1.41]$} & {$[1.79]$} & {$[2.23]$} & {$[4.14]$} & {$[2.55]$} & {$[3.45]$} & & \\
\hline \multirow[t]{2}{*}{ Jul 2007 - May 2011} & -1.18 & -3.70 & 7.79 & 7.90 & 10.07 & 4.18 & 11.25 & $(0.18)$ & $(0.05)$ \\
\hline & {$[-0.21]$} & {$[-0.67]$} & {$[1.44]$} & {$[1.37]$} & {$[1.87]$} & {$[0.87]$} & {$[2.36]$} & & \\
\hline \multicolumn{10}{|c|}{ Panel B. Recursive window } \\
\hline & $P_{1}$ & $P_{2}$ & $P_{3}$ & $P_{4}$ & $P_{5}$ & & BMS & MR & $\mathrm{Up}$ \\
\hline \multirow[t]{2}{*}{ Jan 2001 - May 2011} & -0.42 & 2.35 & 5.68 & 6.73 & 11.74 & & 12.16 & $(0.00)$ & $(0.00)$ \\
\hline & {$[-0.14]$} & {$[0.83]$} & {$[2.13]$} & {$[2.40]$} & {$[4.19]$} & & {$[4.97]$} & & \\
\hline \multirow[t]{2}{*}{ Jan 2001 - Jun 2007} & 0.56 & 5.82 & 3.86 & 7.62 & 11.68 & & 11.12 & $(0.19)$ & $(0.00)$ \\
\hline & {$[0.18]$} & {$[2.07]$} & {$[1.39]$} & {$[2.83]$} & {$[3.91]$} & & {$[4.00]$} & & \\
\hline \multirow[t]{2}{*}{ Jul 2007 - May 2011} & -1.89 & -2.87 & 8.41 & 5.40 & 11.83 & & 13.72 & $(0.20)$ & $(0.01)$ \\
\hline & {$[-0.34]$} & {$[-0.51]$} & {$[1.62]$} & {$[0.94]$} & {$[2.20]$} & & {$[3.07]$} & & \\
\hline \multicolumn{10}{|l|}{ Panel C. In-sample } \\
\hline & $P_{1}$ & $P_{2}$ & $P_{3}$ & $P_{4}$ & $P_{5}$ & & BMS & MR & $\mathrm{Up}$ \\
\hline \multirow[t]{2}{*}{ Jan 2001 - May 2011} & 0.00 & 1.91 & 7.16 & 6.09 & 10.98 & & 10.98 & $(0.11)$ & $(0.00)$ \\
\hline & {$[0.00]$} & {$[0.68]$} & {$[2.58]$} & {$[2.14]$} & {$[4.00]$} & & {$[4.65]$} & & \\
\hline \multirow[t]{2}{*}{ Jan 2001 - Jun 2007} & 1.86 & 4.47 & 6.54 & 6.40 & 10.36 & & 8.50 & $(0.01)$ & $(0.07)$ \\
\hline & {$[0.63]$} & {$[1.52]$} & {$[2.18]$} & {$[2.31]$} & {$[3.65]$} & & {$[3.26]$} & & \\
\hline \multirow[t]{2}{*}{ Jul 2007 - May 2011} & -2.79 & -1.92 & 8.09 & 5.61 & 11.91 & & 14.70 & $(0.15)$ & $(0.01)$ \\
\hline & {$[-0.51]$} & {$[-0.35]$} & {$[1.53]$} & {$[0.97]$} & {$[2.21]$} & & {$[3.34]$} & & \\
\hline
\end{tabular}


Table 4. Order Flow Portfolios: Customer Groups

This table is similar to Table 3 but here we limit the sample to nine developed countries for which we have information about flows of different groups: AM denotes asset managers, HF denotes hedge funds, $\mathrm{CC}$ denotes corporate clients, and PC denotes private clients. Due to the smaller cross-section we build four portfolios. For comparison, we also report results for total flows based on the same nine developed countries (row T9). Flows are standardized by their standard deviation of the previous 60 trading days (rolling window). Average excess returns are annualized (assuming 252 trading days per year). Numbers in brackets are tstatistics based on Newey-West standard errors. Columns 'MR', 'Up', and 'Down' report p-values for tests of return monotonicity. The frequency is daily and the sample is from January 2001 to May 2011.

\begin{tabular}{rrrrrrrrrr}
\hline & $P_{1}$ & $P_{2}$ & $P_{3}$ & $P_{4}$ & Av. & BMS & MR & Up & Down \\
\hline AM & -1.13 & 3.75 & 6.30 & 14.31 & & 15.43 & $(0.00)$ & $(0.00)$ & $(0.95)$ \\
& {$[-0.35]$} & {$[1.24]$} & {$[2.04]$} & {$[4.63]$} & & {$[5.72]$} & & & \\
HF & -0.32 & 6.05 & 6.26 & 9.78 & 10.09 & $(0.04)$ & $(0.00)$ & $(0.89)$ \\
& {$[-0.10]$} & {$[2.04]$} & {$[1.94]$} & {$[3.02]$} & & {$[3.94]$} & & & \\
CO & 6.90 & 5.27 & 7.02 & 2.61 & -4.29 & $(0.35)$ & $(0.95)$ & $(0.09)$ \\
& {$[2.15]$} & {$[1.73]$} & {$[2.16]$} & {$[0.84]$} & {$[-1.66]$} & & & \\
PC & 12.71 & 6.69 & 2.90 & -1.30 & -14.01 & $(0.00)$ & $(0.93)$ & $(0.00)$ \\
& {$[4.06]$} & {$[2.18]$} & {$[0.93]$} & {$[-0.41]$} & & {$[-5.20]$} & & & \\
\hline \multirow{2}{*}{ T9 } & 0.34 & 2.24 & 8.21 & 12.76 & 5.89 & 12.43 & $(0.00)$ & $(0.00)$ & $(0.94)$ \\
& {$[0.10]$} & {$[0.74]$} & {$[2.60]$} & {$[4.17]$} & {$[2.15]$} & {$[4.68]$} & & & \\
\hline
\end{tabular}


Table 5. Cross-sectional regressions: Individual currencies

This table reports Fama-MacBeth type cross-sectional regressions of individual currencies' excess returns on a constant, lagged order flow $\left(O F_{t-1}\right)$, interest rate differentials $\left(\Delta i_{t}\right)$, and lagged excess returns over the previous 60 trading days $\left(r x_{t-60 ; t-1}\right)$. We report results for total flows of all 15 currency pairs (T15), total flows of nine developed countries (T9), asset managers (AM), hedge funds (HF), corporate clients (CC), and private clients (PC). The frequency is daily and the sample is from January 2001 to May 2011.

\begin{tabular}{lrrrrrr}
\hline & T15 & T9 & AM & HF & CC & PC \\
\hline const. & 0.01 & 0.01 & 0.01 & 0.02 & 0.01 & 0.02 \\
& {$[0.83]$} & {$[0.87]$} & {$[0.71]$} & {$[1.51]$} & {$[1.07]$} & {$[1.39]$} \\
$O F_{t-1}$ & 1.60 & 1.78 & 1.72 & 2.60 & -1.13 & -3.29 \\
& {$[3.02]$} & {$[2.19]$} & {$[2.05]$} & {$[3.31]$} & {$[-1.19]$} & {$[-3.72]$} \\
$\Delta i_{t}$ & 1.39 & 1.82 & 1.93 & 1.91 & 2.39 & 1.89 \\
& {$[3.33]$} & {$[2.27]$} & {$[2.38]$} & {$[2.33]$} & {$[2.98]$} & {$[2.38]$} \\
$r x_{t-60 ; t-1}$ & -0.11 & -0.01 & 0.02 & 0.10 & 0.01 & -0.03 \\
& {$[-0.83]$} & {$[-0.04]$} & {$[0.10]$} & {$[0.55]$} & {$[0.09]$} & {$[-0.19]$} \\
\hline$R^{2}$ & 0.21 & 0.18 & 0.19 & 0.19 & 0.18 & 0.18 \\
\hline
\end{tabular}


Table 6. Macro-finance risk factors and excess returns

This table reports univariate regression results of BMS portfolio returns on the Dollar risk factor and $H M L_{F X}$ from Lustig, Roussanov, and Verdelhan (2011), global FX volatility innovations from Menkhoff, Sarno, Schmeling, and Schrimpf (2012a), real IP growth, real M2 growth, CPI inflation, term spread innovations, TED spread innovations, default spread innovations, and TIPS spread innovations. We employ excess returns to factor-mimicking portfolios for all except the first two factors (which are excess returns already) to ensure that the alphas in our regressions can be interpreted. Factor-mimicking portfolios are constructed based on individual currency excess returns.

\begin{tabular}{|c|c|c|c|c|c|c|c|c|c|c|}
\hline & $D O L$ & $H M L_{F X}$ & $V O L_{F X}$ & $I P$ & $M 2$ & $C P I$ & $T S$ & $T E D$ & $D E F$ & $T I P S$ \\
\hline \multicolumn{11}{|c|}{ Panel A. Total order flows (T9) } \\
\hline \multirow[t]{2}{*}{$\alpha$} & 13.61 & 12.43 & 12.66 & 12.46 & 12.29 & 12.35 & 12.85 & 12.31 & 12.56 & 13.12 \\
\hline & {$[4.96]$} & {$[4.63]$} & {$[4.60]$} & {$[4.75]$} & {$[4.66]$} & {$[4.60]$} & {$[4.64]$} & {$[4.58]$} & {$[4.71]$} & {$[4.67]$} \\
\hline \multirow[t]{2}{*}{$\beta$} & -0.26 & -0.02 & 0.01 & -0.68 & -0.03 & 4.70 & 0.03 & 0.00 & 0.01 & -1.64 \\
\hline & {$[-2.45]$} & {$[-0.26]$} & {$[0.62]$} & {$[-0.75]$} & {$[-0.04]$} & {$[0.70]$} & {$[1.67]$} & {$[0.02]$} & {$[0.63]$} & {$[-1.29]$} \\
\hline$R^{2}$ & 0.06 & 0.00 & 0.00 & 0.00 & 0.00 & 0.00 & 0.02 & 0.00 & 0.00 & 0.02 \\
\hline \multicolumn{11}{|c|}{ Panel B. Asset Managers } \\
\hline \multirow[t]{2}{*}{$\alpha$} & 16.61 & 17.32 & 17.53 & 16.00 & 16.78 & 15.48 & 15.56 & 16.66 & 17.15 & 17.12 \\
\hline & {$[5.08]$} & {$[4.85]$} & {$[5.41]$} & {$[5.31]$} & {$[5.46]$} & {$[5.07]$} & {$[4.96]$} & {$[5.19]$} & {$[5.20]$} & {$[5.37]$} \\
\hline \multirow[t]{2}{*}{$\beta$} & -0.20 & -0.20 & 0.07 & -1.67 & 3.19 & -12.51 & 0.00 & 0.04 & 0.07 & -3.04 \\
\hline & {$[-1.15]$} & {$[-1.72]$} & {$[2.32]$} & {$[-1.22]$} & {$[2.03]$} & {$[-1.13]$} & {$[-0.07]$} & {$[2.02]$} & {$[2.18]$} & {$[-1.71]$} \\
\hline$R^{2}$ & 0.03 & 0.06 & 0.10 & 0.02 & 0.10 & 0.03 & 0.00 & 0.04 & 0.10 & 0.06 \\
\hline \multicolumn{11}{|c|}{ Panel C. Hedge Funds } \\
\hline \multirow[t]{2}{*}{$\alpha$} & 9.06 & 7.60 & 7.86 & 9.48 & 8.80 & 9.95 & 9.51 & 8.12 & 8.35 & 8.51 \\
\hline & {$[3.07]$} & {$[2.74]$} & {$[2.92]$} & [3.48] & [3.25] & {$[3.68]$} & {$[3.26]$} & {$[3.08]$} & {$[3.11]$} & [2.99] \\
\hline \multirow[t]{2}{*}{$\beta$} & 0.15 & 0.26 & -0.07 & 1.51 & -2.83 & 11.19 & -0.02 & -0.07 & -0.07 & 2.66 \\
\hline & {$[0.96]$} & {$[2.61]$} & {$[-2.63]$} & [1.91] & {$[-3.04]$} & {$[1.38]$} & {$[-0.55]$} & {$[-3.03]$} & {$[-2.41]$} & {$[1.53]$} \\
\hline$R^{2}$ & 0.02 & 0.12 & 0.12 & 0.02 & 0.10 & 0.02 & 0.01 & 0.14 & 0.11 & 0.05 \\
\hline \multicolumn{11}{|c|}{ Panel D. Corporate Clients } \\
\hline \multirow[t]{2}{*}{$\alpha$} & -3.66 & -4.70 & -4.36 & -3.63 & -4.15 & -3.90 & -3.83 & -4.22 & -4.62 & -4.53 \\
\hline & {$[-1.26]$} & {$[-1.48]$} & {$[-1.44]$} & {$[-1.38]$} & {$[-1.50]$} & {$[-1.59]$} & {$[-1.40]$} & {$[-1.42]$} & {$[-1.58]$} & {$[-1.53]$} \\
\hline \multirow[t]{2}{*}{$\beta$} & -0.09 & 0.07 & -0.01 & -2.00 & -0.12 & 18.80 & 0.02 & 0.00 & -0.02 & 0.85 \\
\hline & {$[-0.49]$} & {$[0.43]$} & {$[-0.22]$} & {$[-1.70]$} & {$[-0.07]$} & {$[1.85]$} & {$[0.46]$} & {$[-0.12]$} & {$[-0.50]$} & {$[0.41]$} \\
\hline$R^{2}$ & 0.00 & 0.01 & 0.00 & 0.03 & 0.00 & 0.05 & 0.00 & 0.00 & 0.01 & 0.00 \\
\hline \multicolumn{11}{|c|}{ Panel E. Private Clients } \\
\hline \multirow[t]{2}{*}{$\alpha$} & -13.10 & -13.08 & -13.47 & -13.80 & -13.89 & -13.95 & -13.45 & -12.91 & -13.54 & -13.66 \\
\hline & {$[-3.89]$} & {$[-3.95]$} & {$[-4.06]$} & {$[-4.22]$} & {$[-4.29]$} & {$[-4.28]$} & {$[-3.95]$} & {$[-4.09]$} & {$[-4.16]$} & [-3.98] \\
\hline \multirow[t]{2}{*}{$\beta$} & -0.17 & -0.10 & 0.02 & -0.66 & 0.17 & 0.15 & 0.03 & 0.04 & 0.02 & -0.58 \\
\hline & {$[-1.68]$} & {$[-1.25]$} & {$[0.64]$} & {$[-0.48]$} & {$[0.17]$} & {$[0.03]$} & [1.08] & {$[1.96]$} & [1.10] & {$[-0.42]$} \\
\hline$R^{2}$ & 0.02 & 0.02 & 0.01 & 0.00 & 0.00 & 0.00 & 0.01 & 0.05 & 0.01 & 0.00 \\
\hline
\end{tabular}


Table 7. Hedge fund risk factors

This table reports univariate regression results of BMS portfolio returns (based on total flows and customer flows) on five hedge fund risk factors from Fung and Hsieh (2001). These risk factors are based on returns to lookback straddles for bonds (BD), currencis (FX), commodities (CM), short-term interest rates (SIR), and equities (EQ). Data for these factors are available until September 2009.

\begin{tabular}{|c|c|c|c|c|c|c|c|c|c|c|}
\hline & $\mathrm{BD}$ & FX & $\mathrm{CM}$ & SIR & EQ & $\mathrm{BD}$ & FX & $\mathrm{CM}$ & $\mathrm{SIR}$ & EQ \\
\hline & \multicolumn{5}{|c|}{ Panel A. Total order flows (T15) } & \multicolumn{5}{|c|}{ Panel B. Total order flows (T9) } \\
\hline \multirow[t]{2}{*}{$\alpha$} & 10.77 & 10.82 & 10.73 & 10.71 & 10.71 & 11.55 & 11.97 & 11.86 & 11.51 & 12.30 \\
\hline & {$[3.86]$} & {$[4.26]$} & {$[4.11]$} & {$[4.49]$} & {$[3.18]$} & {$[3.74]$} & {$[4.18]$} & {$[4.18]$} & {$[4.03]$} & {$[3.88]$} \\
\hline \multirow[t]{2}{*}{$\beta$} & 0.03 & -0.93 & -0.53 & 0.07 & -0.09 & -0.96 & -0.75 & -0.93 & 0.70 & 0.71 \\
\hline & {$[0.02]$} & {$[-0.48]$} & {$[-0.32]$} & {$[0.06]$} & {$[-0.03]$} & {$[-0.48]$} & {$[-0.68]$} & {$[-0.68]$} & {$[2.09]$} & {$[0.44]$} \\
\hline \multirow[t]{2}{*}{$R^{2}$} & 0.00 & 0.01 & 0.00 & 0.00 & 0.00 & 0.00 & 0.00 & 0.00 & 0.01 & 0.00 \\
\hline & \multicolumn{5}{|c|}{ Panel C. Asset Managers } & \multicolumn{5}{|c|}{ Panel D. Hedge Funds } \\
\hline \multirow[t]{2}{*}{$\alpha$} & 17.98 & 16.27 & 16.63 & 15.01 & & 7.68 & 9.01 & 8.63 & 9.73 & 7.89 \\
\hline & {$[4.63]$} & {$[5.29]$} & {$[5.04]$} & {$[5.47]$} & {$[4.47]$} & {$[2.81]$} & {$[3.34]$} & {$[3.02]$} & {$[3.48]$} & {$[2.16]$} \\
\hline \multirow[t]{2}{*}{$\beta$} & 3.83 & 3.46 & 1.94 & 2.61 & 1.96 & -2.84 & -3.59 & -2.28 & -1.69 & -1.59 \\
\hline & {$[1.34]$} & {$[2.54]$} & {$[1.07]$} & {$[3.77]$} & {$[0.82]$} & {$[-1.77]$} & {$[-2.23]$} & {$[-1.00]$} & {$[-1.73]$} & {$[-0.57]$} \\
\hline \multirow[t]{2}{*}{$R^{2}$} & 0.04 & 0.07 & 0.01 & 0.12 & 0.01 & 0.03 & 0.09 & 0.02 & 0.06 & 0.01 \\
\hline & \multicolumn{5}{|c|}{ Panel E. Corporate Clients } & \multicolumn{5}{|c|}{ Panel F. Private Clients } \\
\hline \multirow[t]{2}{*}{$\alpha$} & -4.01 & -4.83 & -5.04 & -4.28 & -6.23 & -13.15 & -14.04 & -13.89 & -13.88 & -13.39 \\
\hline & {$[-1.56]$} & {$[-1.83]$} & {$[-1.91]$} & {$[-1.66]$} & {$[-1.93]$} & {$[-3.66]$} & {$[-3.92]$} & {$[-3.95]$} & {$[-3.90]$} & {$[-3.59]$} \\
\hline \multirow[t]{2}{*}{$\beta$} & 2.36 & -0.98 & -2.39 & -1.08 & -2.44 & 2.09 & 1.34 & 1.06 & -0.11 & 1.02 \\
\hline & {$[1.24]$} & {$[-0.50]$} & {$[-1.10]$} & {$[-0.91]$} & {$[-1.03]$} & {$[1.05]$} & [1.19] & {$[0.59]$} & {$[-0.08]$} & {$[0.52]$} \\
\hline$R^{2}$ & 0.01 & 0.00 & 0.01 & 0.02 & 0.01 & 0.01 & 0.01 & 0.00 & 0.00 & 0.00 \\
\hline
\end{tabular}


Table 8. Risk factors and the cross-section of portfolios

This table reports results for risk factors and currency excess returns using the cross-section of all four portfolios based on asset managers' (AM) and hedge funds' (HF) portfolios. $\beta_{P 1}$ - $\beta_{P 4}$ denote estimates of factor loadings for each of the four portfolios, $\chi^{2}$ denotes the test statistic for a Wald test that all factor loadings are jointly equal to zero (with $p$-value in parentheses), and $M R$ reports the $p$-value for a test of a monotone pattern in factor loadings $\beta_{P 1}-\beta_{P 4}$ (increasing or decreasing pattern, depending on the sign of $\beta_{P 4}-\beta_{P 1}$ ). Estimates are based on GMM with HAC standard errors except for the MR test $p$-value which is based on a stationary bootstrap.

\begin{tabular}{|c|c|c|c|c|c|c|c|c|}
\hline & $H M L_{F X}$ & $V O L_{F X}$ & $M 2$ & $T E D$ & $D E F$ & $B D$ & $F X$ & $S I R$ \\
\hline & \multicolumn{8}{|c|}{ Panel A. Asset Managers } \\
\hline \multirow[t]{2}{*}{$\beta_{P 1}$} & 0.19 & -0.12 & -3.40 & -0.10 & -0.14 & 0.00 & 0.00 & -0.03 \\
\hline & [1.29] & {$[-5.21]$} & {$[-3.71]$} & {$[-5.61]$} & {$[-6.58]$} & {$[0.08]$} & {$[0.18]$} & {$[-2.86]$} \\
\hline \multirow[t]{2}{*}{$\beta_{P 2}$} & 0.20 & -0.11 & -2.71 & -0.09 & -0.13 & 0.00 & 0.00 & -0.03 \\
\hline & {$[1.37]$} & {$[-4.64]$} & {$[-2.29]$} & {$[-5.19]$} & {$[-6.64]$} & {$[-0.19]$} & {$[0.11]$} & [-2.69] \\
\hline \multirow[t]{2}{*}{$\beta_{P 3}$} & 0.37 & -0.16 & -5.21 & -0.13 & -0.18 & -0.02 & -0.01 & -0.04 \\
\hline & {$[2.05]$} & {$[-5.02]$} & {$[-5.92]$} & {$[-5.59]$} & {$[-15.41]$} & {$[-1.23]$} & {$[-0.23]$} & {$[-2.58]$} \\
\hline \multirow[t]{2}{*}{$\beta_{P 4}$} & -0.01 & -0.05 & -0.21 & -0.06 & -0.07 & 0.04 & 0.04 & 0.00 \\
\hline & {$[-0.13]$} & {$[-2.89]$} & {$[-0.15]$} & {$[-3.33]$} & {$[-2.22]$} & {$[1.87]$} & {$[2.07]$} & {$[-0.33]$} \\
\hline \multirow[t]{2}{*}{$\chi^{2}$} & 12.01 & 33.87 & 58.70 & 45.32 & 249.83 & 5.51 & 45.81 & 42.60 \\
\hline & $(0.01)$ & $(0.00)$ & $(0.00)$ & $(0.00)$ & $(0.00)$ & $(0.24)$ & $(0.00)$ & $(0.00)$ \\
\hline \multirow[t]{2}{*}{$M R$} & $(0.80)$ & $(0.87)$ & $(0.89)$ & $(0.87)$ & $(0.79)$ & $(0.54)$ & $(0.43)$ & $(0.80)$ \\
\hline & \multicolumn{8}{|c|}{ Panel B. Hedge Funds } \\
\hline \multirow[t]{2}{*}{$\beta_{P 1}$} & 0.06 & -0.08 & -1.15 & -0.06 & -0.10 & 0.02 & 0.03 & -0.02 \\
\hline & {$[0.67]$} & {$[-4.61]$} & {$[-0.76]$} & {$[-4.00]$} & {$[-3.00]$} & {$[0.81]$} & {$[1.44]$} & {$[-2.93]$} \\
\hline \multirow[t]{2}{*}{$\beta_{P 2}$} & 0.12 & -0.09 & -1.63 & -0.08 & -0.10 & 0.02 & 0.02 & -0.02 \\
\hline & {$[1.00]$} & {$[-5.66]$} & {$[-1.38]$} & {$[-5.69]$} & {$[-5.63]$} & {$[1.50]$} & {$[0.76]$} & {$[-2.40]$} \\
\hline \multirow[t]{2}{*}{$\beta_{P 3}$} & 0.29 & -0.13 & -5.46 & -0.10 & -0.17 & -0.02 & -0.01 & -0.03 \\
\hline & [1.49] & {$[-3.23]$} & {$[-4.74]$} & {$[-4.44]$} & {$[-6.74]$} & {$[-0.94]$} & {$[-0.16]$} & {$[-1.60]$} \\
\hline \multirow[t]{2}{*}{$\beta_{P 4}$} & 0.33 & -0.15 & -3.98 & -0.13 & -0.17 & -0.01 & -0.01 & -0.04 \\
\hline & {$[1.92]$} & {$[-5.44]$} & {$[-3.09]$} & {$[-5.61]$} & {$[-7.32]$} & {$[-0.80]$} & {$[-0.32]$} & {$[-2.52]$} \\
\hline \multirow[t]{2}{*}{$\chi^{2}$} & 20.00 & 39.86 & 33.16 & 38.03 & 104.18 & 5.22 & 21.18 & 13.77 \\
\hline & $(0.00)$ & $(0.00)$ & $(0.00)$ & $(0.00)$ & $(0.00)$ & $(0.27)$ & $(0.00)$ & $(0.01)$ \\
\hline$M R$ & $(0.00)$ & $(0.00)$ & $(0.59)$ & $(0.00)$ & $(0.07)$ & $(0.22)$ & $(0.01)$ & $(0.00)$ \\
\hline
\end{tabular}


Table 9. Cross-sectional regressions: More control variables

This table reports results for cross-sectional regressions of individual currencies' excess returns on lagged order flows, denoted as $O F_{t-1}$, and an additional characteristic (e.g., interest rate differentials) or risk measure (e.g., volatility betas), denoted as $x$. These additional right-hand-side variables are interest rate differentials $(\Delta i)$, short-term lagged currency returns over one, five, and 60 trading days $\left(r x_{1}, r x_{5}, r x_{60}\right)$, lagged bid-ask spreads $(b a)$, global FX volatility betas $\left(\beta_{F X}\right)$, Dollar risk factor betas $\left(\beta_{D}\right)$, and $H M L_{F X}$ betas $\left(\beta_{H}\right)$.

\begin{tabular}{|c|c|c|c|c|c|c|c|c|}
\hline & $\Delta i$ & $r x_{1}$ & $r x_{5}$ & $r x_{60}$ & $b a$ & $\beta_{F X}$ & $\beta_{D}$ & $\beta_{H}$ \\
\hline & \multicolumn{8}{|c|}{ Panel A. Total flows (T15) } \\
\hline \multirow[t]{2}{*}{$O F_{t-1}$} & 1.90 & 2.37 & 2.37 & 2.03 & 1.87 & 1.55 & 0.02 & 0.02 \\
\hline & {$[3.46]$} & {$[4.24]$} & {$[4.07]$} & {$[3.82]$} & {$[3.32]$} & {$[3.06]$} & {$[3.54]$} & {$[3.07]$} \\
\hline \multirow[t]{2}{*}{$x$} & 1.28 & 0.00 & 0.00 & 0.00 & 0.00 & -0.25 & 1.06 & 2.85 \\
\hline & {$[3.21]$} & {$[0.21]$} & {$[-0.47]$} & {$[-0.59]$} & {$[1.32]$} & {$[-1.43]$} & {$[1.10]$} & [1.96] \\
\hline \multirow[t]{2}{*}{$R^{2}$} & 0.25 & 0.22 & 0.23 & 0.24 & 0.23 & 0.27 & 0.29 & 0.30 \\
\hline & \multicolumn{8}{|c|}{ Panel B. Total flows (T9) } \\
\hline \multirow[t]{2}{*}{$O F_{t-1}$} & 2.30 & 2.73 & 2.77 & 2.66 & 3.31 & 2.30 & 0.02 & 0.02 \\
\hline & {$[2.84]$} & {$[3.71]$} & {$[3.74]$} & {$[3.63]$} & {$[4.11]$} & {$[3.41]$} & {$[3.56]$} & [3.18] \\
\hline \multirow[t]{2}{*}{$x$} & 1.59 & 0.03 & 0.00 & 0.00 & 0.00 & -0.30 & 0.87 & 4.22 \\
\hline & {$[2.02]$} & {$[2.50]$} & {$[-0.63]$} & {$[0.23]$} & {$[0.22]$} & {$[-1.30]$} & {$[0.62]$} & [1.93] \\
\hline \multirow[t]{2}{*}{$R^{2}$} & 0.33 & 0.32 & 0.32 & 0.33 & 0.27 & 0.35 & 0.35 & 0.37 \\
\hline & \multicolumn{8}{|c|}{ Panel C. Asset Managers (AM) } \\
\hline \multirow[t]{2}{*}{$O F_{t-1}$} & 2.42 & 2.87 & 2.92 & 2.57 & 3.76 & 1.94 & 0.02 & 0.02 \\
\hline & {$[3.05]$} & {$[2.99]$} & {$[3.38]$} & {$[3.30]$} & {$[4.01]$} & {$[2.54]$} & {$[2.91]$} & [1.94] \\
\hline \multirow[t]{2}{*}{$x$} & 1.73 & 0.04 & 0.00 & 0.00 & 0.00 & 0.00 & 0.90 & 3.64 \\
\hline & {$[2.17]$} & {$[2.87]$} & {$[-0.39]$} & {$[0.32]$} & {$[1.06]$} & {$[-1.16]$} & {$[0.65]$} & [1.62] \\
\hline \multirow[t]{2}{*}{$R^{2}$} & 0.34 & 0.32 & 0.32 & 0.33 & 0.27 & 0.35 & 0.35 & 0.37 \\
\hline & \multicolumn{8}{|c|}{ Panel D. Hedge Funds (HF) } \\
\hline \multirow[t]{2}{*}{$O F_{t-1}$} & 2.56 & 2.27 & 2.27 & 2.31 & 1.74 & 3.36 & 0.03 & 0.03 \\
\hline & [3.75] & {$[3.02]$} & [3.35] & {$[2.81]$} & {$[2.18]$} & [3.99] & [2.95] & [3.50] \\
\hline \multirow[t]{2}{*}{$x$} & 1.55 & 0.03 & -0.01 & 0.00 & 0.00 & 0.00 & -0.15 & 4.51 \\
\hline & {$[1.97]$} & {$[2.71]$} & {$[-1.17]$} & {$[0.66]$} & {$[0.44]$} & {$[-1.20]$} & {$[-0.11]$} & [2.03] \\
\hline \multirow[t]{2}{*}{$R^{2}$} & 0.34 & 0.32 & 0.33 & 0.34 & 0.27 & 0.35 & 0.35 & 0.38 \\
\hline & \multicolumn{8}{|c|}{ Panel E. Corporate Clients (CC) } \\
\hline \multirow[t]{2}{*}{$O F_{t-1}$} & -1.16 & -1.15 & -0.79 & -1.02 & -1.11 & -1.24 & -0.01 & -0.01 \\
\hline & {$[-1.36]$} & {$[-1.26]$} & {$[-0.84]$} & {$[-1.05]$} & {$[-1.26]$} & {$[-1.44]$} & {$[-1.08]$} & {$[-0.85]$} \\
\hline \multirow[t]{2}{*}{$x$} & 2.18 & 0.02 & 0.00 & 0.00 & 0.00 & 0.00 & 0.69 & 3.73 \\
\hline & {$[2.74]$} & {$[1.96]$} & {$[-0.89]$} & {$[0.17]$} & {$[0.67]$} & {$[-1.73]$} & {$[0.50]$} & [1.69] \\
\hline \multirow[t]{2}{*}{$R^{2}$} & 0.33 & 0.31 & 0.32 & 0.33 & 0.27 & 0.35 & 0.35 & 0.37 \\
\hline & \multicolumn{8}{|c|}{ Panel F. Private Clients (PC) } \\
\hline \multirow[t]{2}{*}{$O F_{t-1}$} & -2.60 & -2.63 & -2.79 & -3.26 & -3.05 & -2.63 & -0.03 & -0.03 \\
\hline & {$[-3.07]$} & {$[-3.28]$} & {$[-3.52]$} & {$[-3.90]$} & {$[-3.40]$} & {$[-3.15]$} & {$[-3.59]$} & {$[-3.58]$} \\
\hline \multirow[t]{2}{*}{$x$} & 1.38 & 0.03 & 0.00 & 0.00 & 0.00 & 0.00 & -0.09 & 3.11 \\
\hline & {$[1.77]$} & {$[2.45]$} & {$[-0.35]$} & {$[0.16]$} & {$[-0.05]$} & {$[-1.30]$} & {$[-0.07]$} & [1.42] \\
\hline$R^{2}$ & 0.34 & 0.32 & 0.33 & 0.34 & 0.28 & 0.35 & 0.36 & 0.37 \\
\hline
\end{tabular}


Figure 1. Cumulative excess returns: Total flows
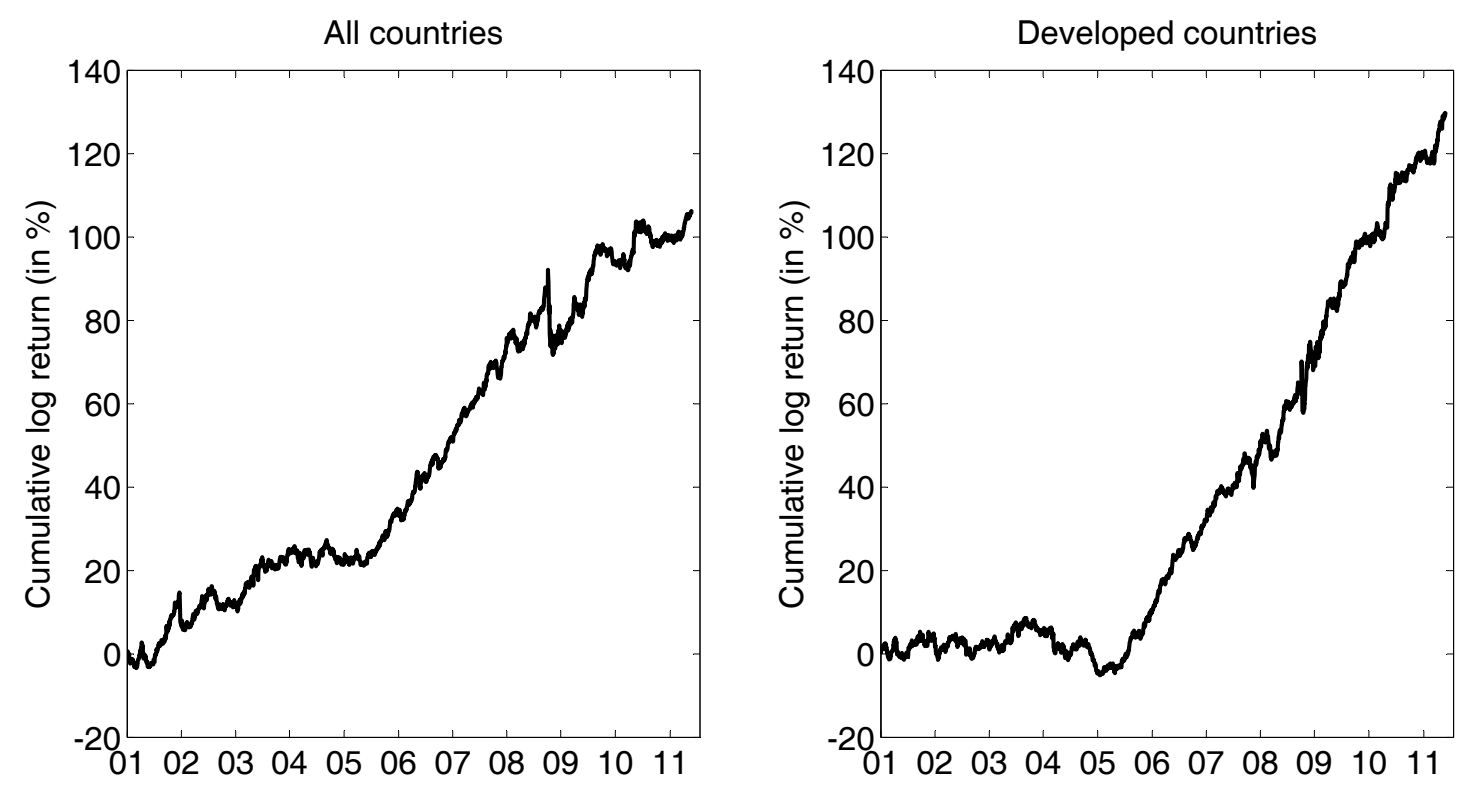

This figure shows cumulative log excess returns for a long-short portfolio based on total order flows. The left panel is based on the total sample of all 15 currencies whereas the right panel is based on a subset of nine developed currencies (against the USD). 
Figure 2. Cumulative excess returns: Customer flows
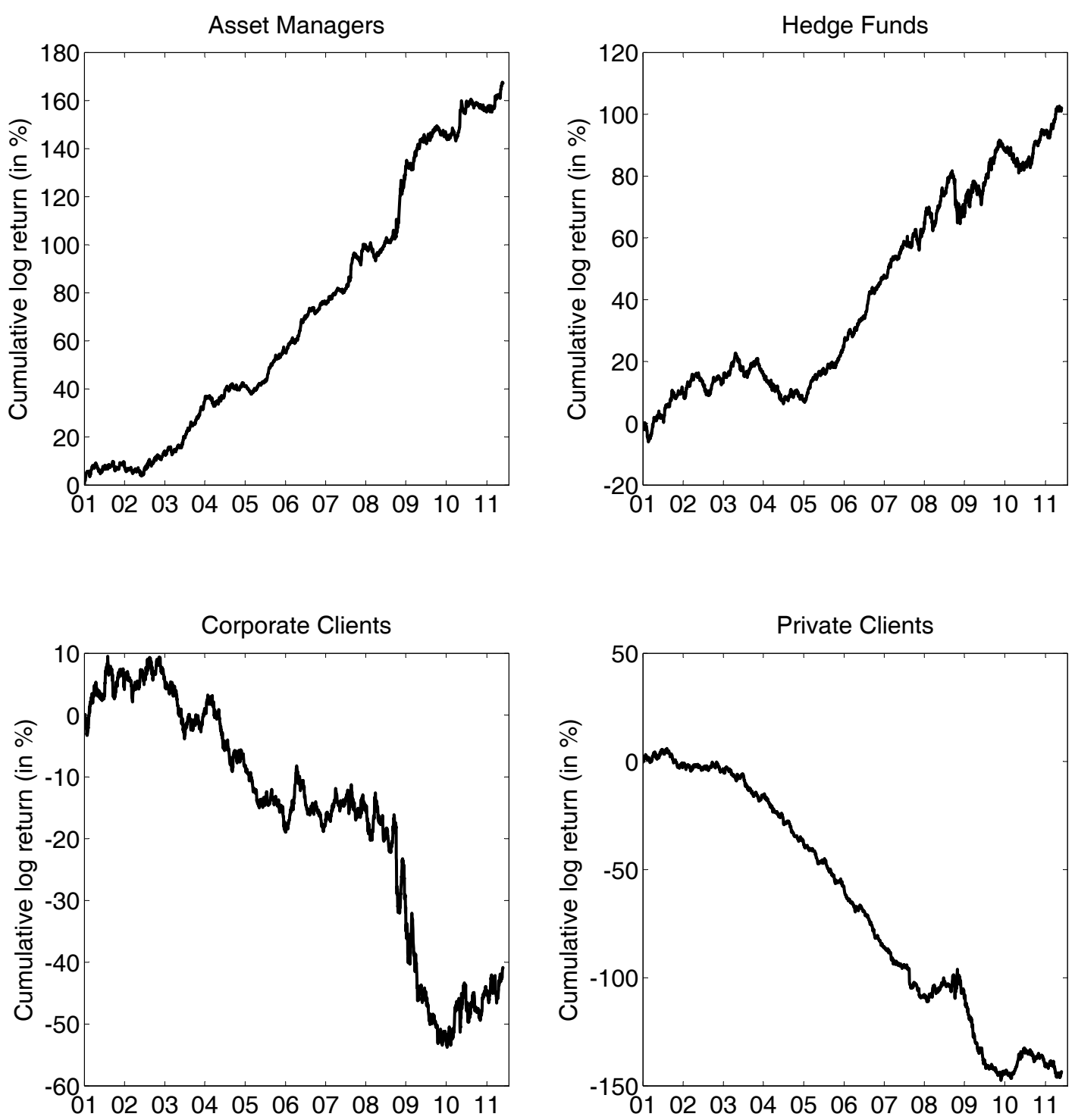

This figure shows cumulative log excess returns for long-short portfolios based on customer order flows. 
Figure 3. Cumulative post-formation exchange rate changes: Total flows
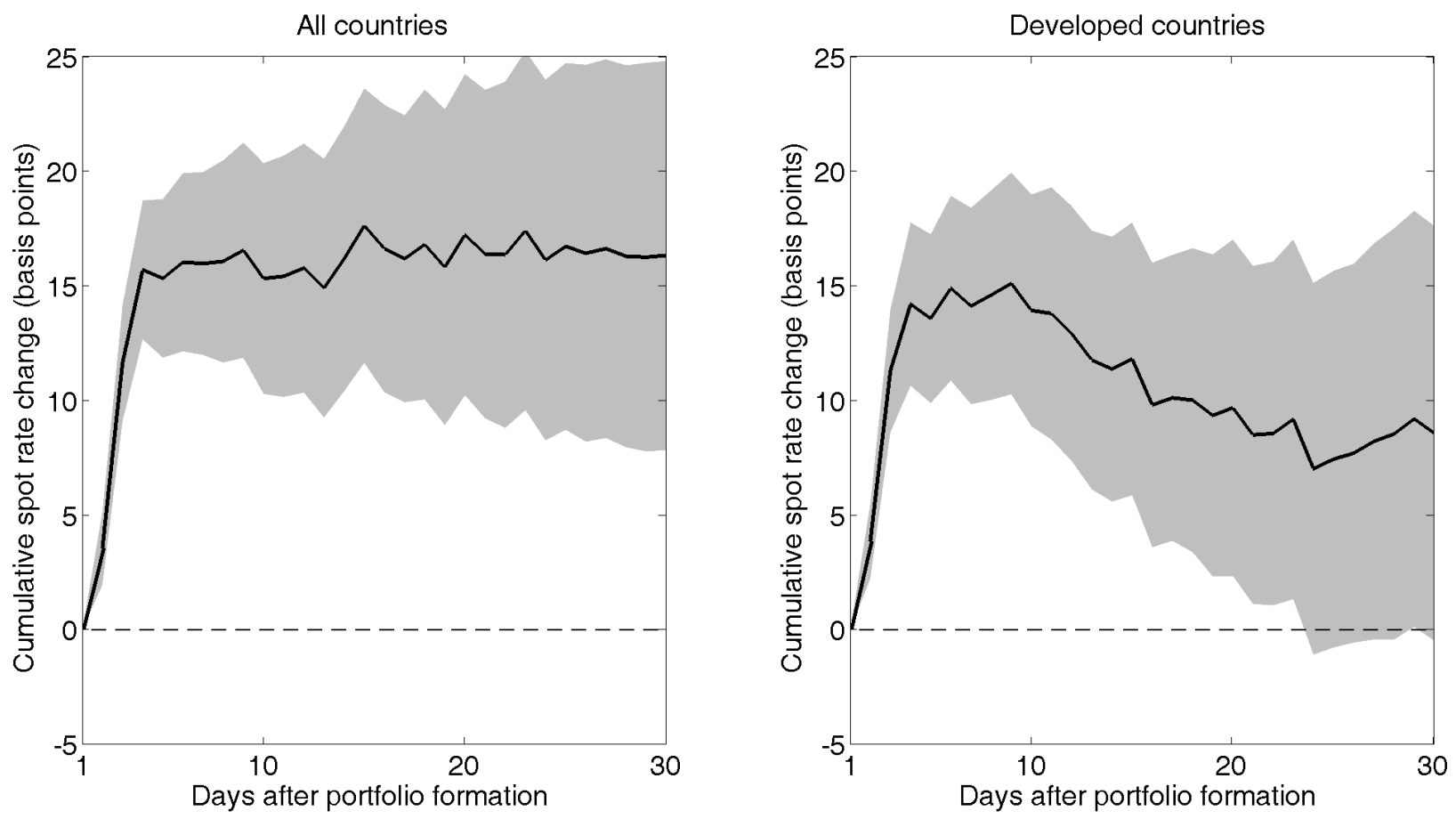

This figure shows average cumulative spot exchange rate changes for a long-short portfolio based on total order flows over the first 30 days after portfolio formation. We use daily data so that post-formation periods overlap. The left panel shows results for all 15 countries in our sample whereas the right panel shows results for a subset of 9 developed countries. Shaded areas correspond to a $95 \%$ confidence interval obtained from a moving-block bootstrap with 1,000 repetitions. 
Figure 4. Cumulative post-formation exchange rate changes: Customer flows
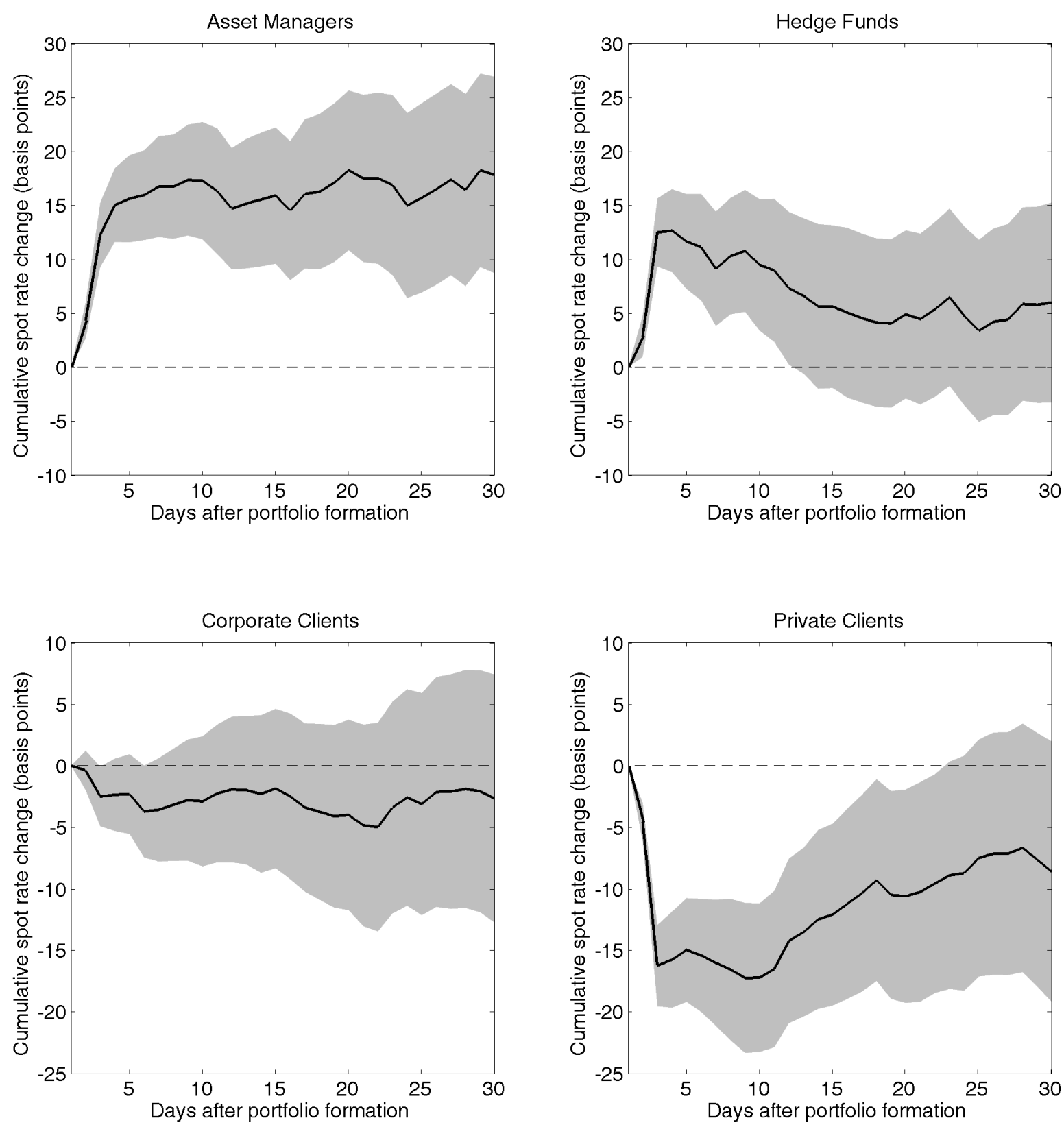

This figure shows average cumulative spot exchange rate changes for a long-short portfolio based on customer order flows over the first 30 days after portfolio formation. We use daily data so that post-formation periods overlap. All plots are based on a subset of 9 developed countries. Shaded areas correspond to a $95 \%$ confidence interval obtained from a moving-block bootstrap with 1,000 repetitions. 
Figure 5. Rebalancing frequency and net excess returns: Total flows
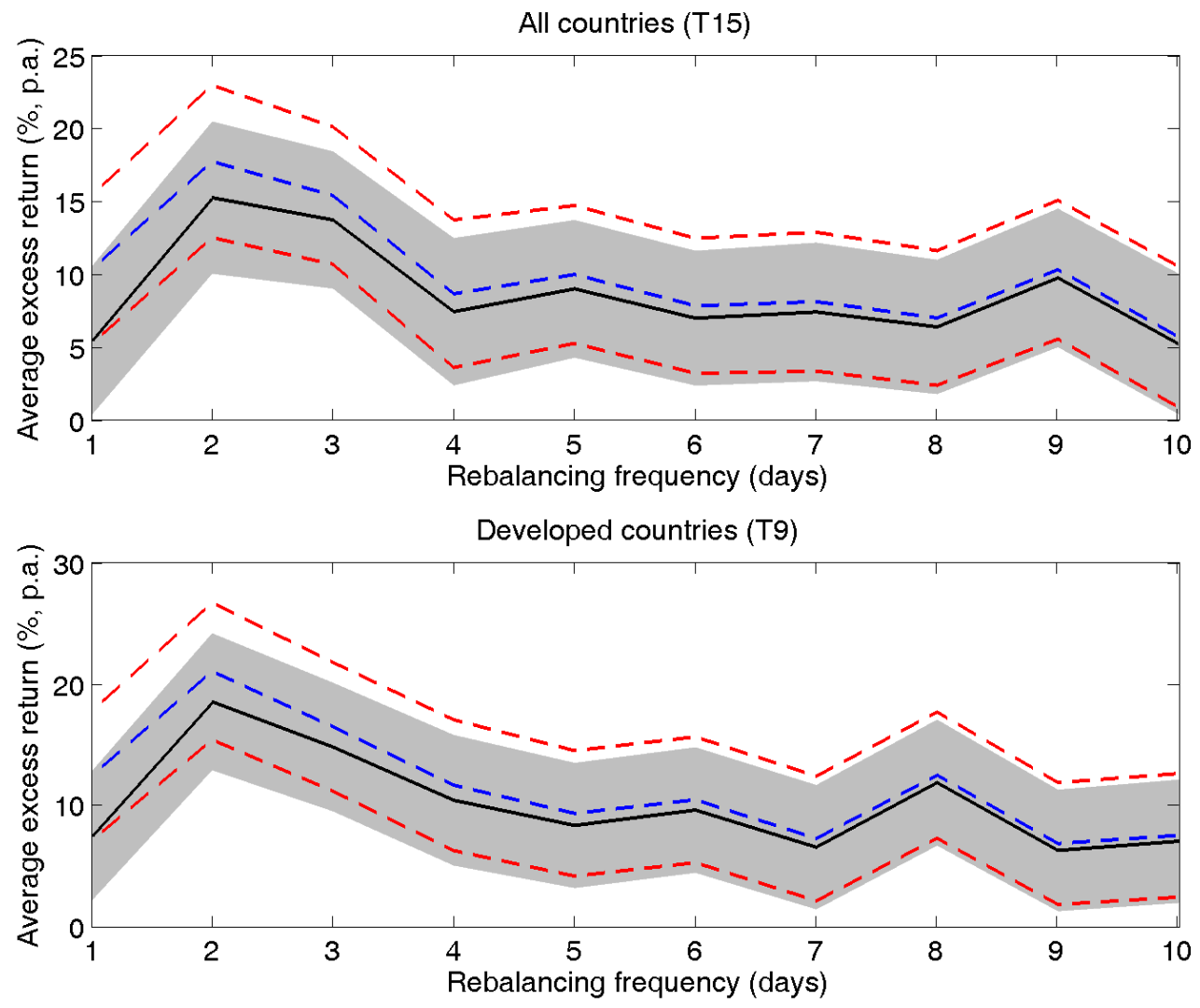

This figure shows average annualized excess returns for the BMS portfolio based on all 15 currencies' flows (left panel) and flows for the nine developed countries (right panel) for different rebalancing frequencies ranging from one to ten days. The dotted lines show excess returns and a 95\% confidence interval based on Newey-West standard errors before transaction costs whereas the solid line and shaded area show net excess returns and a $95 \%$ confidence interval based on Newey-West standard errors after transaction costs. 
Figure 6. Rebalancing frequency and net excess returns: Customer flows
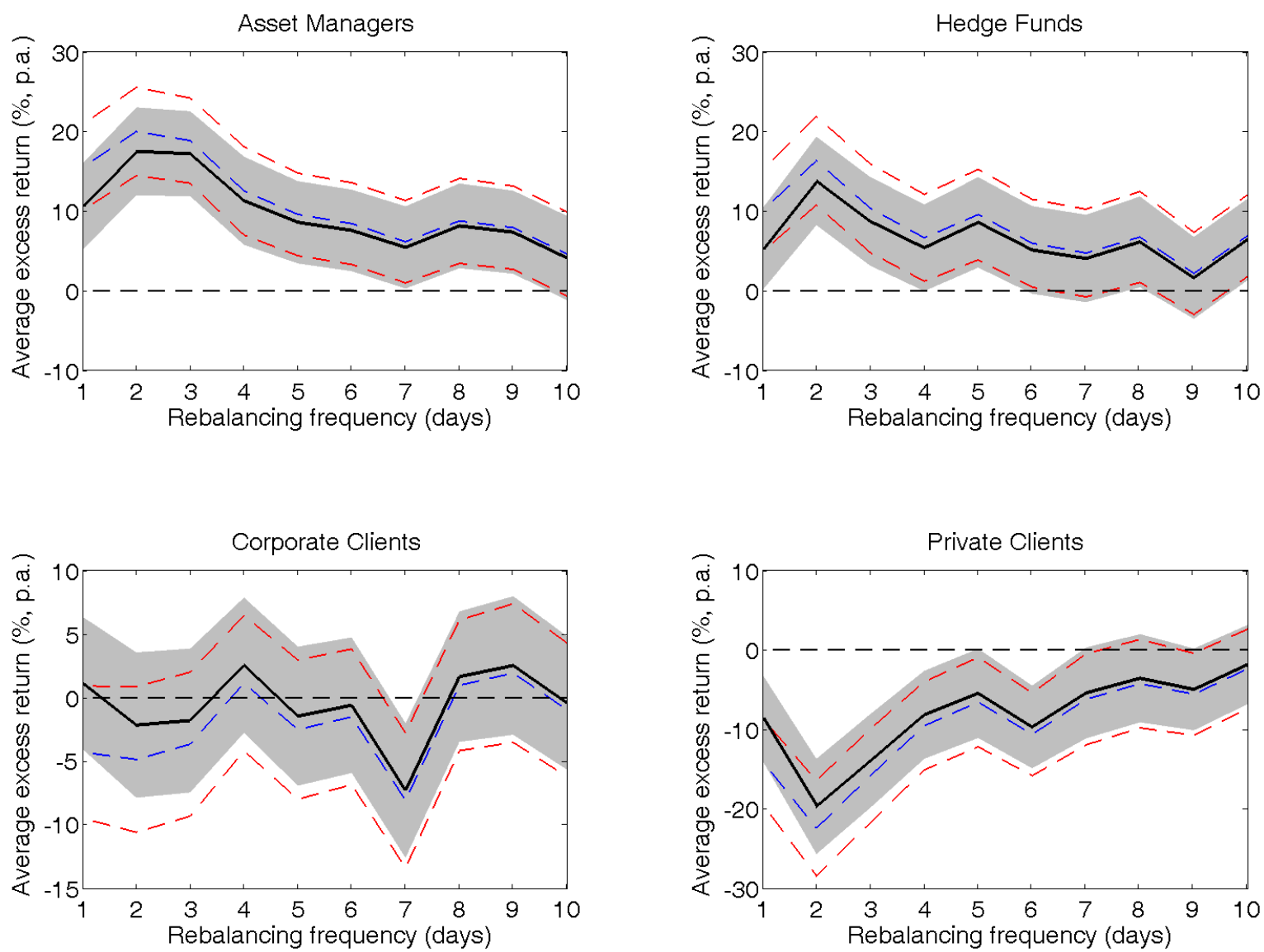

This figure is similar to Figure 5 but shows results for BMS portfolios based on customer order flows instead of total order flows. 


\section{Web Appendix to accompany \\ The Cross-Section of Currency Order Flow Portfolios}

Table A.1. Correlation between customer groups' order flows

This table reports correlation coefficients between flows of customer groups for nine major currencies and for a pooled sample over all currencies.

\begin{tabular}{lrrrrrr}
\hline \multicolumn{7}{c}{ Correlation coefficients } \\
& AM/HF & AM/CC & AM/PC & HF/CC & HF/PC & CC/PC \\
\hline EUR & -0.04 & -0.05 & -0.05 & -0.10 & -0.20 & -0.05 \\
JPY & 0.05 & -0.05 & -0.12 & -0.02 & -0.20 & -0.05 \\
GBP & -0.03 & 0.02 & -0.11 & -0.02 & -0.17 & 0.02 \\
CHF & 0.01 & -0.09 & -0.08 & -0.07 & -0.20 & -0.09 \\
AUD & 0.00 & 0.03 & -0.02 & -0.06 & -0.07 & 0.03 \\
NZD & 0.00 & -0.05 & -0.06 & 0.01 & -0.03 & -0.05 \\
CAD & -0.04 & -0.08 & -0.05 & -0.01 & -0.15 & -0.08 \\
SEK & -0.03 & -0.01 & -0.01 & -0.02 & 0.04 & -0.01 \\
NOK & -0.02 & -0.04 & -0.01 & -0.03 & 0.03 & -0.04 \\
\hline \multicolumn{7}{c}{} \\
Pooled & -0.01 & -0.04 & -0.05 & -0.03 & -0.10 & -0.04 \\
\hline
\end{tabular}


Table A.2. Order Flow Portfolios: Exchange Rate Changes

This table shows average portfolio exchange rate changes for five portfolios $\left(P_{1}, \ldots, P_{5}\right)$ sorted on lagged order flow. Sorting is done based on standardized total flows of all customers. Column "Av" shows average excess returns across all currencies, column "BMS" (bought minus sold) reports average excess returns to investing in $P_{5}$ and shorting $P_{1}$. Panel $\mathrm{B}$ reports the same information for spot exchange rate changes instead of excess returns. Flows are standardized by their standard deviation (i) using a rolling window over the previous 60 trading days (Panel A), (ii) using a recursive scheme with 60 days initialization horizon (Panel B), and (iii) their in-sample standard deviation. Average spot rate changes are annualized (assuming 252 trading days per year). Numbers in brackets are t-statistics based on Newey-West standard errors. The frequency is daily and the sample is from January 2001 - May 2011.

\begin{tabular}{|c|c|c|c|c|c|c|c|}
\hline \multicolumn{8}{|c|}{ Panel A. Rolling window } \\
\hline & $P_{1}$ & $P_{2}$ & $P_{3}$ & $P_{4}$ & $P_{5}$ & Av. & BMS \\
\hline \multirow[t]{2}{*}{ Jan 2001 - May 2011} & -1.28 & -0.64 & 4.01 & 4.13 & 10.20 & 3.28 & 11.48 \\
\hline & {$[-0.45]$} & {$[-0.22]$} & {$[1.47]$} & {$[1.41]$} & {$[3.72]$} & {$[1.40]$} & {$[4.57]$} \\
\hline \multirow[t]{2}{*}{ Jan 2001 - Jun 2007} & -0.24 & 2.56 & 2.70 & 2.73 & 11.35 & 3.82 & 11.59 \\
\hline & {$[-0.08]$} & {$[0.86]$} & {$[0.98]$} & {$[0.91]$} & {$[4.02]$} & {$[1.68]$} & {$[4.25]$} \\
\hline \multirow[t]{2}{*}{ Jul 2007 - May 2011} & -2.85 & -5.45 & 5.99 & 6.23 & 8.46 & 2.48 & 11.31 \\
\hline & {$[-0.52]$} & {$[-0.98]$} & {$[1.11]$} & {$[1.08]$} & {$[1.57]$} & {$[0.52]$} & {$[2.37]$} \\
\hline \multicolumn{8}{|c|}{ Panel B. Recursive window } \\
\hline & $P_{1}$ & $P_{2}$ & $P_{3}$ & $P_{4}$ & $P_{5}$ & & BMS \\
\hline \multirow{2}{*}{ Jan 2001 - May 2011} & -2.40 & 0.71 & 3.40 & 4.32 & 10.33 & & 12.73 \\
\hline & {$[-0.83]$} & {$[0.25]$} & {$[1.27]$} & {$[1.50]$} & {$[3.70]$} & & {$[5.17]$} \\
\hline \multirow[t]{2}{*}{ Jan 2001 - Jun 2007} & -1.42 & 4.17 & 1.02 & 4.62 & 10.61 & & 12.03 \\
\hline & {$[-0.46]$} & {$[1.46]$} & {$[0.36]$} & {$[1.60]$} & {$[3.58]$} & & {$[4.28]$} \\
\hline \multirow[t]{2}{*}{ Jul 2007 - May 2011} & -3.87 & -4.49 & 6.97 & 3.87 & 9.90 & & 13.77 \\
\hline & {$[-0.69]$} & {$[-0.80]$} & {$[1.34]$} & {$[0.67]$} & {$[1.84]$} & & {$[3.08]$} \\
\hline \multicolumn{8}{|c|}{ Panel C. In-sample } \\
\hline & $P_{1}$ & $P_{2}$ & $P_{3}$ & $P_{4}$ & $P_{5}$ & & BMS \\
\hline \multirow[t]{2}{*}{ Jan 2001 - May 2011} & -1.17 & -0.98 & 4.63 & 4.26 & 9.68 & & 10.85 \\
\hline & {$[-0.41]$} & {$[-0.34]$} & {$[1.68]$} & {$[1.49]$} & {$[3.51]$} & & {$[4.57]$} \\
\hline \multirow[t]{2}{*}{ Jan 2001 - Jun 2007} & 1.16 & 0.78 & 3.34 & 4.44 & 9.42 & & 8.27 \\
\hline & {$[0.40]$} & {$[0.26]$} & {$[1.13]$} & {$[1.55]$} & {$[3.30]$} & & {$[3.14]$} \\
\hline \multirow[t]{2}{*}{ Jul 2007 - May 2011} & -4.67 & -3.61 & 6.58 & 4.01 & 10.07 & & 14.74 \\
\hline & {$[-0.84]$} & {$[-0.65]$} & {$[1.25]$} & {$[0.70]$} & {$[1.87]$} & & {$[3.34]$} \\
\hline
\end{tabular}


Table A.3. Order Flow Portfolios: Demeaning flows

This table is similar to Table 3 but here we present results for total flows (T15 and T9) and customer groups' flows and we standardize order flows by subtracting the rolling mean and dividing by the rolling standard deviation. The frequency is daily and the sample is from January 2001 - May 2011.

\begin{tabular}{rrrrrrrr}
\hline & P1 & P2 & P3 & P4 & P5 & Av & BMS \\
\hline T15 & -0.68 & 5.02 & 5.54 & 5.67 & 11.16 & 5.34 & 11.84 \\
& {$[-0.24]$} & {$[1.86]$} & {$[1.95]$} & {$[2.07]$} & {$[3.88]$} & {$[2.26]$} & {$[4.89]$} \\
T9 & 0.11 & 3.21 & 6.12 & 13.60 & & & 13.49 \\
& {$[0.03]$} & {$[1.08]$} & {$[1.91]$} & {$[4.40]$} & & & {$[5.25]$} \\
\hline AM & -0.28 & 4.64 & 3.45 & 14.50 & & & 14.77 \\
& {$[-0.08]$} & {$[1.56]$} & {$[1.07]$} & {$[4.77]$} & & & {$[5.44]$} \\
HF & -0.04 & 6.29 & 5.26 & 9.95 & & 9.99 \\
& {$[-0.01]$} & {$[2.09]$} & {$[1.69]$} & {$[3.02]$} & & & {$[3.88]$} \\
CO & 7.91 & 5.41 & 4.85 & 3.75 & & & -4.17 \\
& {$[2.48]$} & {$[1.82]$} & {$[1.54]$} & {$[1.17]$} & & & {$[-1.50]$} \\
PC & 12.11 & 6.37 & 5.05 & -2.09 & & & -14.19 \\
& {$[3.77]$} & {$[2.15]$} & {$[1.60]$} & {$[-0.63]$} & & & {$[-5.00]$} \\
\hline
\end{tabular}


Table A.4. Order Flow Portfolios: Customer Groups and Exchange Rate Changes This table is similar to Table 4 but here we report spot exchange rate changes and not excess returns.

\begin{tabular}{lrrrrrr}
\hline & $P_{1}$ & $P_{2}$ & $P_{3}$ & $P_{4}$ & Av. & BMS \\
\hline AM & -1.65 & 2.97 & 5.62 & 13.86 & & 15.52 \\
& {$[-0.51]$} & {$[0.98]$} & {$[1.81]$} & {$[4.49]$} & & {$[5.75]$} \\
HF & -0.90 & 5.32 & 5.70 & 9.25 & & 10.15 \\
& {$[-0.29]$} & {$[1.80]$} & {$[1.77]$} & {$[2.85]$} & & {$[3.96]$} \\
CO & 6.30 & 4.47 & 6.37 & 2.26 & -4.04 \\
& {$[1.97]$} & {$[1.47]$} & {$[1.96]$} & {$[0.73]$} & & {$[-1.56]$} \\
PC & 12.08 & 5.99 & 2.28 & -1.84 & & -13.91 \\
& {$[3.85]$} & {$[1.96]$} & {$[0.73]$} & {$[-0.57]$} & & {$[-5.16]$} \\
\hline T9 & -0.31 & 1.54 & 7.58 & 12.24 & 5.27 & 12.55 \\
& {$[-0.09]$} & {$[0.51]$} & {$[2.40]$} & {$[4.00]$} & {$[1.93]$} & {$[4.72]$} \\
\hline
\end{tabular}


Table A.5. Correlation of excess returns

This table reports correlation coefficients between excess returns of different BMS portfolios based on (i) lagged total flows of all 15 currency pairs (T15), (ii) lagged total flows of nine developed countries (T9), (iii) lagged flows of asset managers (AM), (iv) lagged flows of hedge funds, (v) lagged flows of corporate clients (CC), and lagged flows of private clients (PC). All flows are standardized by their lagged volatility over a 60 -day rolling window. The frequency is daily and the sample period is January 2001 to Ma 2011.

\begin{tabular}{lrrrrr}
\hline & T15 & T9 & AM & HF & CC \\
\hline T15 & 1.00 & & & & \\
T9 & 0.63 & 1.00 & & & \\
AM & 0.27 & 0.42 & 1.00 & & \\
HF & 0.30 & 0.42 & 0.06 & 1.00 & \\
CC & 0.00 & -0.06 & -0.08 & -0.13 & 1.00 \\
PC & -0.04 & -0.02 & -0.07 & 0.03 & 0.01 \\
\hline
\end{tabular}

Table A.6. Risk factors and portfolios based on total flows (T15)

The setup of this table is identical to Table 6 but here we show results for portfolios based on total flows and all 15 countries in our sample.

\begin{tabular}{rrrrrrrrrrr}
\hline \multicolumn{1}{l}{ Panel A. Macro-finance risk factors } \\
\hline & $D O L$ & $H M L_{F X}$ & $V O L_{F X}$ & $I P$ & $M 2$ & $C P I$ & $T S$ & $T E D$ & $D E F$ & $T I P S$ \\
\hline$\alpha$ & 9.64 & 9.17 & 9.50 & 10.38 & 9.93 & 10.27 & 9.66 & 9.44 & 9.35 & 9.28 \\
& {$[3.41]$} & {$[3.12]$} & {$[3.31]$} & {$[4.34]$} & {$[3.95]$} & {$[4.30]$} & {$[3.61]$} & {$[3.50]$} & {$[3.52]$} & {$[3.18]$} \\
$\beta$ & 0.11 & 0.12 & -0.03 & -0.89 & -0.68 & 8.78 & -0.03 & -0.03 & -0.04 & 1.79 \\
& {$[0.55]$} & {$[0.87]$} & {$[-0.64]$} & {$[-0.95]$} & {$[-0.54]$} & {$[1.07]$} & {$[-0.98]$} & {$[-0.99]$} & {$[-0.98]$} & {$[0.76]$} \\
$R^{2}$ & 0.01 & 0.02 & 0.01 & 0.01 & 0.01 & 0.01 & 0.02 & 0.02 & 0.03 & 0.02 \\
\hline
\end{tabular}


Table A.7. Order flow-weighted BMS portfolios

This table shows returns for BMS portfolios based on total flows and customer flows but here we employ portfolio weights directly based on lagged order flows. For each trading day $t$, we cross-sectionally standardize order flows, rescale these standardized flows so that they sum to two in absolute value, and then use these rescaled and standardized flows as portfolio weights for day $t$ to $t+1$. Numbers in squared brackets are based on Newey/West standard errors. The frequency is daily and the sample is from January 2001 - May 2011.

\begin{tabular}{lrrrrrr}
\hline & T15 & T9 & AM & HF & CO & PC \\
\hline Mean & 12.70 & 11.12 & 13.94 & 6.61 & -1.94 & -9.77 \\
$t$ & 5.07 & 4.70 & 5.86 & 2.91 & -0.89 & -4.27 \\
St. Dev. & 8.38 & 7.60 & 7.72 & 7.46 & 7.04 & 7.12 \\
Sharpe Ratio & 1.52 & 1.46 & 1.81 & 0.89 & -0.28 & -1.37 \\
Skewness & 0.25 & 1.42 & 1.76 & 0.09 & -0.12 & -0.20 \\
Kurtosis & 19.63 & 33.82 & 28.54 & 11.75 & 12.87 & 11.05 \\
Maximum & 6.57 & 7.79 & 7.42 & 3.95 & 2.96 & 3.21 \\
Minimum & -5.33 & -3.68 & -2.46 & -3.69 & -3.95 & -4.12 \\
\hline
\end{tabular}


Table A.8. Order Flow Portfolios: Sensitivity to individual currencies

This table show average annualized excess returns to BMS portfolios based on total flows, asset managers (AM) flows, hedge fund (HF) flows, corporate clients (CC) flows, and private clients (PC) flows for a setting in which we disregard one of the available currencies in our sample. We do this for each available currency and the first column indicates which currency is left out when computing returns to the BMS portfolio. Hence, BMS returns for total flows are based on 14 currencies and BMS returns for customer flows are based on 8 currencies instead of 15 and 9 currencies, respectively. Numbers in brackets are based on Newey/West standard errors.

\begin{tabular}{|c|c|c|c|c|c|c|c|c|c|c|}
\hline & \multicolumn{2}{|c|}{ Total flows } & \multicolumn{2}{|c|}{$\mathrm{AM}$} & \multicolumn{2}{|c|}{$\mathrm{HF}$} & \multicolumn{2}{|c|}{$\mathrm{CC}$} & \multicolumn{2}{|c|}{$\mathrm{PC}$} \\
\hline & $\mathrm{rx}$ & $t$ & $r x$ & $t$ & $r x$ & $t$ & $\mathrm{rx}$ & $t$ & $\mathrm{rx}$ & $t$ \\
\hline EUR & 10.79 & [4.12] & 15.40 & [5.35] & 8.86 & [3.10] & -2.15 & {$[-0.78]$} & -14.62 & {$[-5.23]$} \\
\hline JPY & 8.26 & [3.34] & 9.62 & [3.95] & 11.30 & [4.73] & -3.13 & {$[-1.33]$} & -9.12 & {$[-3.87]$} \\
\hline GBP & 10.18 & [3.99] & 15.29 & [5.65] & 8.95 & [3.35] & -3.04 & {$[-1.17]$} & -13.65 & {$[-4.93]$} \\
\hline CHF & 10.29 & [4.09] & 13.58 & [5.03] & 11.49 & [4.51] & -2.08 & {$[-0.79]$} & -16.31 & {$[-5.90]$} \\
\hline AUD & 10.39 & [4.18] & 10.39 & [4.03] & 9.78 & [3.83] & -5.58 & {$[-2.19]$} & -10.77 & {$[-4.26]$} \\
\hline NZD & 9.35 & [3.67] & 14.75 & [5.52] & 8.16 & [3.15] & -2.22 & {$[-0.87]$} & -11.93 & {$[-4.45]$} \\
\hline CAD & 11.98 & {$[4.70]$} & 14.70 & [5.34] & 9.65 & [3.81] & -4.07 & {$[-1.61]$} & -10.98 & {$[-4.12]$} \\
\hline SEK & 9.33 & [3.70] & 15.51 & [5.76] & 6.32 & [2.28] & -4.46 & {$[-1.76]$} & -14.91 & {$[-5.45]$} \\
\hline NOK & 10.04 & [3.91] & 16.52 & [6.00] & 9.38 & [3.72] & -3.37 & {$[-1.24]$} & -16.20 & {$[-5.84]$} \\
\hline MXN & 10.10 & {$[4.06]$} & & & & & & & & \\
\hline BRL & 11.22 & {$[4.56]$} & & & & & & & & \\
\hline ZAR & 6.71 & [2.79] & & & & & & & & \\
\hline KRW & 11.75 & {$[4.78]$} & & & & & & & & \\
\hline SGD & 10.84 & {$[4.27]$} & & & & & & & & \\
\hline HKD & 11.68 & {$[4.75]$} & & & & & & & & \\
\hline
\end{tabular}

